ARTICLE

DOI: $10.1038 / s 41467-018-06443-3$

\title{
A room-temperature sodium-sulfur battery with high capacity and stable cycling performance
}

\author{
Xiaofu Xu ${ }^{1,2}$, Dong Zhou ${ }^{3}$, Xianying Qin ${ }^{1,2}$, Kui Lin ${ }^{1,2}$, Feiyu Kang ${ }^{1,2}$, \\ Baohua Li ${ }^{1,2}$, Devaraj Shanmukaraj ${ }^{4}$, Teofilo Rojo ${ }^{4}$, Michel Armand ${ }^{4} \&$ Guoxiu Wang (1) ${ }^{3}$
}

High-temperature sodium-sulfur batteries operating at $300-350^{\circ} \mathrm{C}$ have been commercially applied for large-scale energy storage and conversion. However, the safety concerns greatly inhibit their widespread adoption. Herein, we report a room-temperature sodium-sulfur battery with high electrochemical performances and enhanced safety by employing a "cocktail optimized" electrolyte system, containing propylene carbonate and fluoroethylene carbonate as co-solvents, highly concentrated sodium salt, and indium triiodide as an additive. As verified by first-principle calculation and experimental characterization, the fluoroethylene carbonate solvent and high salt concentration not only dramatically reduce the solubility of sodium polysulfides, but also construct a robust solid-electrolyte interface on the sodium anode upon cycling. Indium triiodide as redox mediator simultaneously increases the kinetic transformation of sodium sulfide on the cathode and forms a passivating indium layer on the anode to prevent it from polysulfide corrosion. The as-developed sodium-sulfur batteries deliver high capacity and long cycling stability.

\footnotetext{
${ }^{1}$ Graduate School at Shenzhen, Tsinghua University, Shenzhen 518055, China. ${ }^{2}$ School of Materials Science and Engineering, Tsinghua University, Beijing 100084, China. ${ }^{3}$ School of Mathematical and Physical Sciences, University of Technology Sydney, Sydney, NSW 2007, Australia. ${ }^{4}$ CIC ENERGIGUNE, Parque Tecnológico de Álava, Miñano 01510, Spain. These authors contributed equally: Xiaofu Xu, Dong Zhou. Correspondence and requests for materials should be addressed to B.L. (email: libh@mail.sz.tsinghua.edu.cn) or to M.A. (email: marmand@cicenergigune.com)

or to G.W. (email: Guoxiu.Wang@uts.edu.au)
} 
T o date, batteries based on alkali metal-ion intercalating cathode and anode materials, such as lithium-ion batteries, have been widely used in modern society from portable electronics to electric vehicles ${ }^{1}$. However, batteries based on such intercalation chemistry can only deliver limited energy density, which cannot meet the growing demand for large-scale energy storage $^{2}$. Consequently, alkali metal-sulfur batteries based on a conversion chemistry have attracted tremendous attention due to the high-energy density ${ }^{3}$, non-toxicity, and low cost of sulfur $(S)^{4}$. From sustainability and economic points of view, sodium $(\mathrm{Na})$ is a better option than lithium (Li) to couple with sulfur cathode, because of the analogous chemical properties but much higher natural abundance of $\mathrm{Na}$ compared with $\mathrm{Li}^{5,6}$. Traditional hightemperature $\mathrm{Na}-\mathrm{S}$ batteries were first commercialized in utilityscale stationary power applications in 2002, based on the following reaction ${ }^{7}$ :

$$
2 \mathrm{Na}+n \mathrm{~S} \leftrightarrow \mathrm{Na}_{2} \mathrm{~S}_{n}(n \geq 3)
$$

This rechargeable battery system has significant advantages of high theoretical energy density $\left(760 \mathrm{Wh} \mathrm{kg}^{-1}\right.$, based on the total mass of sulfur and $\mathrm{Na}$ ), high efficiency $(\sim 100 \%)$, excellent cycling life and low cost of electrode materials, which make it an ideal choice for stationary energy storage ${ }^{8,9}$. However, the operating temperature of this system is generally as high as $300-3500^{\circ} \mathrm{C}$ to ensure a sufficient conductivity of sodium $\beta$-alumina solid-electrolyte and keep the polysulfides in a molten state, far exceeding the melting points of $\mathrm{Na}\left(98^{\circ} \mathrm{C}\right)$ and sulfur $\left(115^{\circ} \mathrm{C}\right)^{10}$. Such high temperature not only increases the cost of operation and maintenance, but also brings serious safety hazard due to the highly active molten electrodes, which directly restraints the widespread applications of high-temperature $\mathrm{Na}-\mathrm{S}$ batteries ${ }^{5,8}$. As a result, great efforts have been devoted to lower the working temperature and develop room-temperature $\mathrm{Na}-\mathrm{S}$ batteries with enhanced safety.

Room-temperature $\mathrm{Na}-\mathrm{S}$ batteries have been reported since $2006^{11}$. They have an increased energy density $\left(1274 \mathrm{Wh} \mathrm{kg}^{-1}\right)$ compared with high-temperature Na-S batteries ${ }^{12}$, because $\mathrm{Na}_{2} \mathrm{~S}$ instead of $\mathrm{Na}$ polysulfides is the final discharge product ${ }^{13,14}$ :

$$
2 \mathrm{Na}+p \mathrm{~S} \leftrightarrow \mathrm{Na}_{2} \mathrm{~S}_{p}(p \geq 1)
$$

However, room-temperature $\mathrm{Na}-\mathrm{S}$ batteries generally suffered from low reversible capacity, self-discharging, and serious cycling problems. This is mainly due to the poor compatibility between electrodes and electrolyte ${ }^{12,15}$. As for the sulfur cathode, Na polysulfides formed as intermediates during the charge/discharge processes are highly soluble in liquid electrolytes. They can easily shuttle to the $\mathrm{Na}$ anode and undergo redox reactions to form lower-order polysulfides, depositing on the $\mathrm{Na}$ anode and leading to the loss of active materials and an interfacial deterioration. This greatly decreases the cycling stability of $\mathrm{Na}-\mathrm{S}$ batteries ${ }^{16}$. Moreover, the cathodic reaction from sulfur to $\mathrm{Na}_{2} \mathrm{~S}$ always accompanies huge volumetric changes, which can easily cause active material shedding ${ }^{14}$. Meanwhile, poor kinetics of the transition from short-chain $\mathrm{Na}$ polysulfides or $\mathrm{Na}_{2} \mathrm{~S}$ to long-chain polysulfides leads to low Coulombic efficiency ${ }^{17}$. As for the anode, the highly reactive $\mathrm{Na}$ metal can react with most organic electrolyte solvents and $\mathrm{Na}$ salts, and then forms a solidelectrolyte interface (SEI) layer featuring ionic conduction but electronic insulation ${ }^{18,19}$. The strength of the SEI layer generally cannot bear the mechanical deformation during $\mathrm{Na}$-ion plating/stripping processes, and hence leads to formation of surface defects and then growth of dendrites from these defects ${ }^{20}$. Such $\mathrm{Na}$ dendrites can pierce through the separator, and cause serious safety problems such as short circuits with thermal runaway ${ }^{21}$. They also result in a continuous damage/regeneration of the SEI upon prolonged cycling, which significantly decreases the Coulombic efficiency of batteries ${ }^{22}$. Furthermore, the polysulfides can diffuse through the SEI layer and corrode the Na anode, which causes irreversible capacity loss ${ }^{23}$. All these drawbacks have severely hindered the development of room-temperature $\mathrm{Na}-\mathrm{S}$ batteries.

Many efforts have been devoted to overcome the above problems, including infusing sulfur into a conductive matrix ${ }^{16,24,25}$, surface coatings on sulfur or introducing additives in cathode composition $^{26}$, applying sulfides as cathode materials ${ }^{17,27}$, employing functionalized separators or interlayers ${ }^{28-30}$, and optimizing the electrolyte components. Among them, employing innovative electrolytes have been proposed as one of the most promising strategies to address the inherent drawbacks of roomtemperature $\mathrm{Na}-\mathrm{S}$ batteries without sacrificing the energy density or introducing tedious preparation process ${ }^{8,15,31}$. However, to date, there has still been a lack of fundamental breakthroughs in electrolyte development, which can provide a satisfactory energy density with stable long-term cycling.

Herein, we provide fundamental scientific study on the electrochemical properties of carbonate-based electrolyte in roomtemperature $\mathrm{Na}-\mathrm{S}$ batteries, and report a multifunctional carbonate-based electrolyte consisting of propylene carbonate (PC) and fluoroethylene carbonate (FEC) as co-solvents, highly concentrated bis(trifluoromethane)sulfonimide sodium (NaTFSI) salt, and indium triiodide $\left(\mathrm{InI}_{3}\right)$ additive. The solubility of $\mathrm{Na}$ polysulfides has been efficiently suppressed via the high salt concentration and FEC-rich solvent. Meanwhile, the Na metal anode is effectively protected by an indium (In) layer formed from an $\mathrm{In}^{3+}$ redox reaction and a fluorine (F)-rich stable SEI film. In addition, the irreversible $\mathrm{Na}_{2} \mathrm{~S}$ formed during the charging process is remarkably oxidized by $\mathrm{I}_{3}{ }^{-}$from the $\mathrm{InI}_{3}$ additive, which greatly increases the Coulombic efficiency. The electrode/ electrolyte interfacial phenomena were analyzed by experimental characterizations and theoretical calculations. The as-developed $\mathrm{Na}-\mathrm{S}$ batteries exhibited outstanding performances with a specific capacity of $1170 \mathrm{mAh} \mathrm{g}^{-1}$ (based on the mass of sulfur) at $0.1 \mathrm{C}$ and an extended cycle life.

\section{Results}

Design and characterization of the electrolytes. In this study, multiporous carbon fibers (MPCFs) with a large BrunauerEmmett-Teller (BET) surface area of $2475 \mathrm{~m}^{2} \mathrm{~g}^{-1}$ were synthesized as the matrix material for sulfur storage (the corresponding synthesis route and characterization of MPCFs are shown in Supplementary Figs. 1 and 2). S@MPCF electrodes were fabricated using sodium carboxymethyl cellulose $(\mathrm{CMCNa})$ as the binder (which can form a strong S-O bond with sulfur to greatly enhance the reversible capacity of $\mathrm{Na}-\mathrm{S}$ batteries; details are shown in Supplementary Fig. 3). Considering room-temperature $\mathrm{Na}-\mathrm{S}$ batteries with ether-based electrolytes (such as tetraethylene glycoldimethyl ether (TEGDME) and a combination of 1,3dioxolane/1,2-dimethoxyethane (DOL/DME)) usually suffer from limited capacity and cycle life ${ }^{28,32}$, PC (a representative carbonate ester commonly used in sodium-ion batteries ${ }^{33}$ ) is coupled with NaTFSI salts as the baseline electrolyte (details are shown in Supplementary Figs. 4 and 5). It should be noticed that in Li-S batteries, the nucleophilic sulfide anions actively react with carbonate solvents via nucleophilic addition or substitution reaction, which results in a rapid capacity fading 34 . However, the side reactions between $\mathrm{Na}$ polysulfides and carbonate solvents are much less severe than those between Li polysulfides and carbonate solvents (Supplementary Fig. 6). This may be due to the fact that the larger ionic radius of $\mathrm{Na}^{+}$than $\mathrm{Li}^{+}$leads to less dissociation in polar solvents, which results in a lower reactivity of 


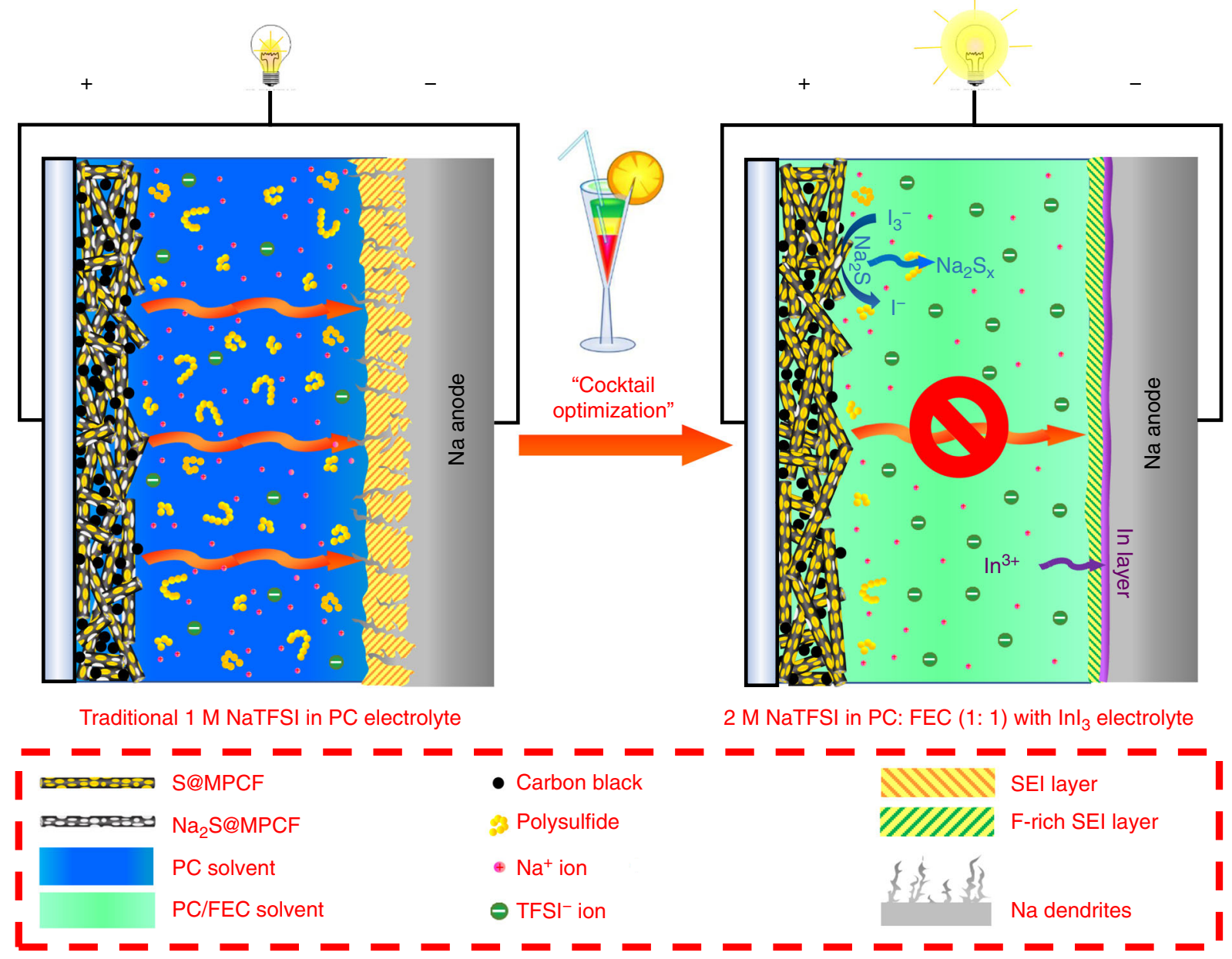

Fig. 1 Schematic illustration of room-temperature Na-S batteries using (left) conventional 1 M NaTFSI in PC electrolyte and (right) 2 M NaTFSI in PC: FEC

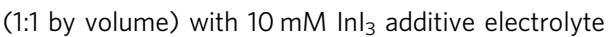

$\mathrm{Na}^{+}$-polysulfide ${ }^{-}$ion pairs than that of $\mathrm{Li}^{+}$-polysulfide ${ }^{-}$ion pairs ${ }^{35,36}$. Therefore, the negative effect of such side reactions on the electrochemical performance of $\mathrm{Na}-\mathrm{S}$ batteries is negligible.

To further improve the limited capacity $\left(\sim 400 \mathrm{mAh} \mathrm{g}^{-1}\right)$ and cycle life of $1 \mathrm{M}$ NaTFSI in PC electrolyte-based $\mathrm{Na}-\mathrm{S}$ cells, we developed a novel carbonate-based electrolyte. Figure 1 shows a schematic illustration of the optimization mechanism for this electrolyte in room-temperature $\mathrm{Na}-\mathrm{S}$ batteries. In conventional PC-based electrolyte, it is widely believed that the transitions from solid-state short-chain polysulfides or $\mathrm{Na}_{2} \mathrm{~S}$ to long-chain polysulfides are kinetically difficult due to dramatic volume change caused by the large ionic size of $\mathrm{Na}^{+37,38}$. The nonconductive unconverted $\mathrm{Na}_{2} \mathrm{~S}$ usually accumulates on the cathode, reducing the charge transfer rate and blocking the ion accessibility, which results in serious polarization as well as gradual capacity fading ${ }^{38}$. Moreover, the shuttle of highly soluble $\mathrm{Na}$ polysulfides not only causes the loss of active materials in the cathode, but also leads to the formation of a SEI layer with high Ohmic resistance. Additionally, the growth of $\mathrm{Na}$ dendrites also results in low Coulombic efficiency, which is associated with greater safety hazards (Fig. 1, left). Conversely, in our new electrolyte composed of highly concentrated NaTFSI salt and $\mathrm{InI}_{3}$ additive dissolved in PC/FEC (1:1 by volume) co-solvents, the FEC solvent and high salt concentration not only significantly decrease the solubility of $\mathrm{Na}$ polysulfides, but also form a stable Frich SEI and a dendrite-free Na surface during cycling. The $\mathrm{In}^{3+}$ ions from the $\mathrm{InI}_{3}$ additive construct a passivating In layer on the anode, which protects against polysulfide corrosion. Meanwhile, the iodide $\left(\mathrm{I}^{-}\right)$ions can be reversibly oxidized into triiodide ions $\left(\mathrm{I}_{3}{ }^{-}\right)$in the charging process ${ }^{39}$, facilitating the transformation of $\mathrm{Na}_{2} \mathrm{~S}$ to $\mathrm{Na}$ polysulfides and, therefore, lowering the high irreversibility of $\mathrm{Na}_{2} \mathrm{~S}$ during the charge/discharge process (Fig. 1, right). Such "cocktail optimization" of electrolyte is expected to ensure an excellent cycling stability for both cathodes and anodes in room-temperature $\mathrm{Na}-\mathrm{S}$ batteries.

Figure $2 \mathrm{a}$ shows the ionic conductivities of $1 \mathrm{M} \mathrm{NaTFSI}$ in PC, $1 \mathrm{M}$ NaTFSI in PC: FEC (1:1 by volume), $2 \mathrm{M}$ NaTFSI in PC: FEC (1:1 by volume) and $2 \mathrm{M}$ NaTFSI in PC: FEC (1:1 by volume) with $10 \mathrm{mM} \mathrm{InI}_{3}$. The plots of $\log \sigma$ vs. $T^{-1}$ for all the electrolyte samples exhibits a non-linear relationship, which is well fitted by the Vogel-Tamman-Fulcher (VTF) empirical equation below ${ }^{40}$ :

$$
\sigma=\sigma_{\mathrm{o}} T^{-1 / 2} \exp \left(-\frac{E_{\mathrm{a}}}{R\left(T-T_{\mathrm{o}}\right)}\right)
$$

where $E_{\mathrm{a}}$ is the pseudo-activation energy, $\sigma_{\mathrm{o}}$ is the pre-exponential factor, $T_{\mathrm{o}}$ is the ideal glass transition temperature, and $R$ is the gas constant. The fitting parameters and ionic conductivity values are listed in Supplementary Table 2. It can be seen that the ionic conductivities of electrolytes slightly decrease with increasing $\mathrm{Na}$ salt concentration and FEC proportion due to the rise in viscosity $^{41}$ (Supplementary Fig. 7), and are almost unchanged after the addition of the small amount of $\mathrm{InI}_{3}$ additive. The $2 \mathrm{M}$ NaTFSI in PC: FEC (1:1 by volume) with $\mathrm{InI}_{3}$ electrolyte can 
a

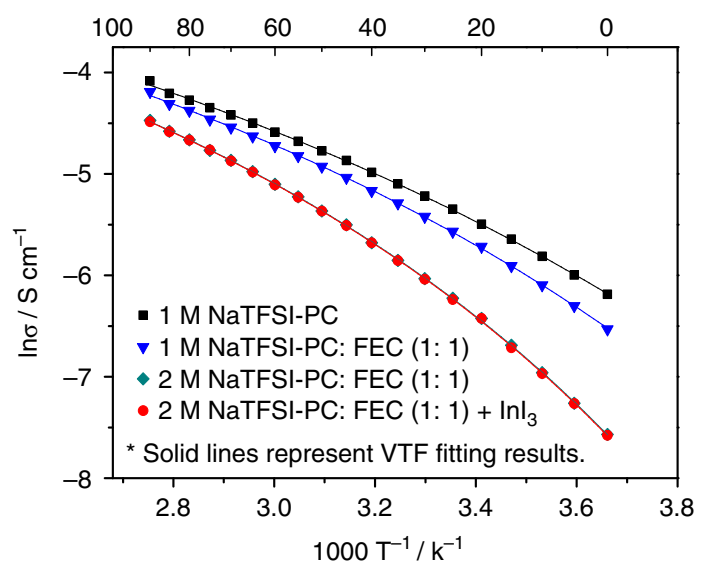

c
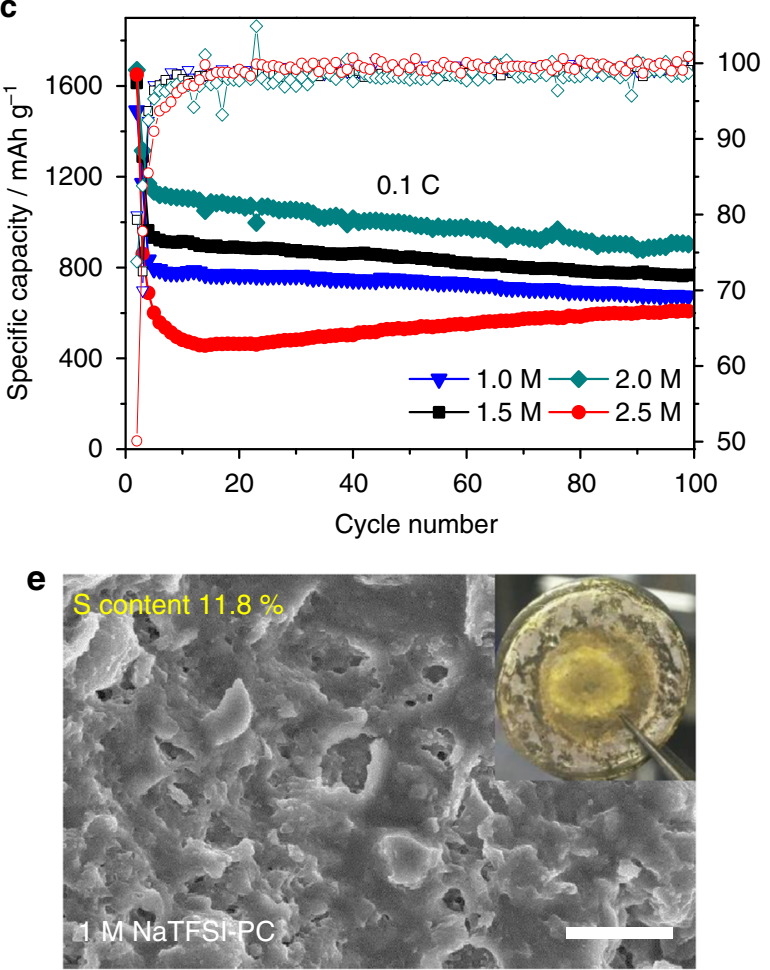

g

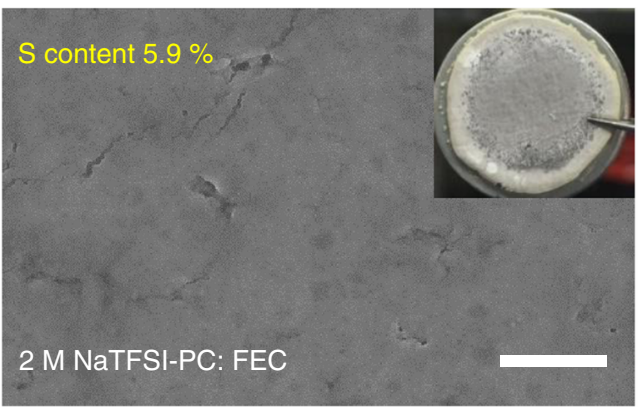

b

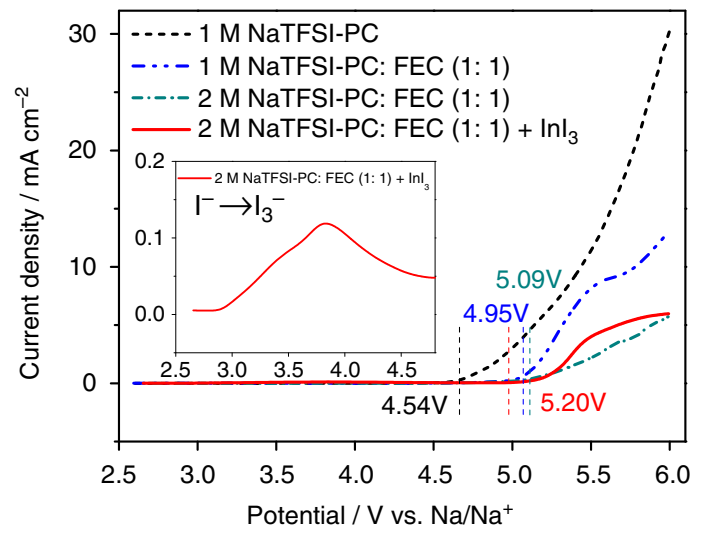

d

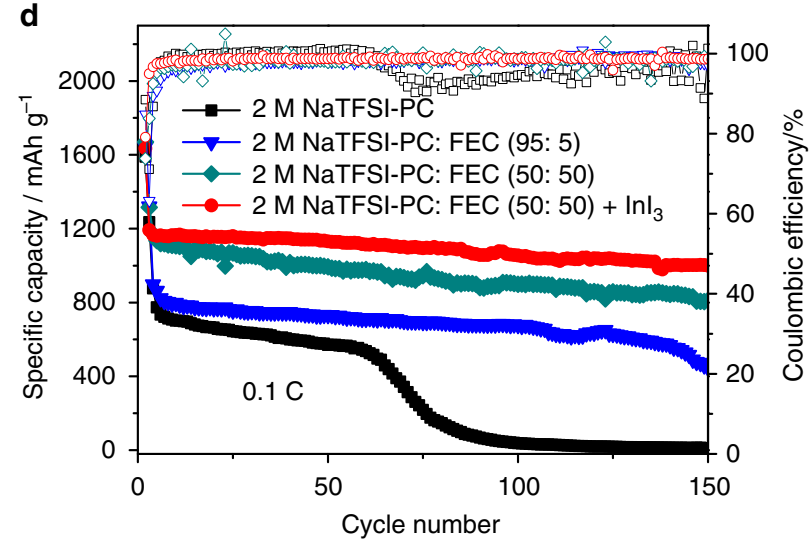

$\mathbf{f}$

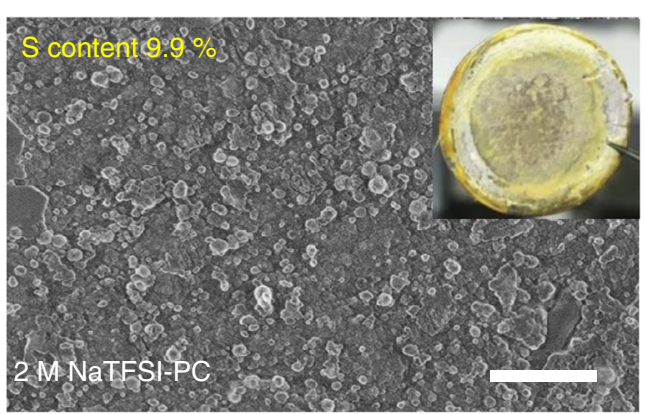

h

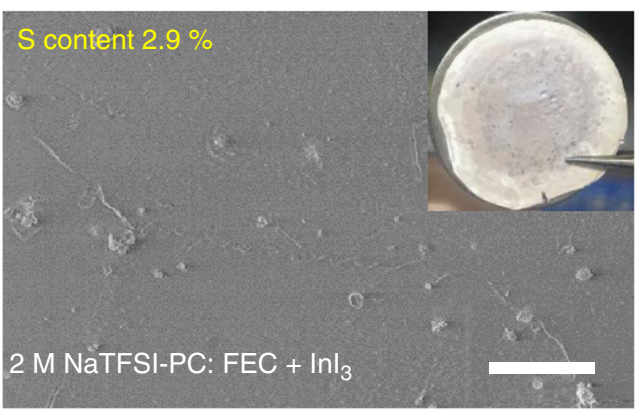

Fig. 2 Characterization of electrolytes. a lonic conductivities of $1 \mathrm{M} \mathrm{NaTFSI}$ in PC, 1 M NaTFSI in PC: FEC (1:1 by volume), 2 M NaTFSI in PC: FEC (1:1 by volume) and $2 \mathrm{M} \mathrm{NaTFSI}$ in PC: FEC (1:1 by volume) with $10 \mathrm{mM} \mathrm{Inl}_{3}$ samples. The plots represent the experimental data while the solid lines represent VTF fitting results. $\mathbf{b} L S V$ s of the above four electrolyte samples at a scan rate of $0.1 \mathrm{mV} \mathrm{s}^{-1}$ using stainless steel as the working electrode, and $\mathrm{Na}$ as the counter and the reference electrodes. c Cycling performances of Na/S@MPCF cells using electrolytes with various concentration of NaTFSI in PC: FEC (1:1 by volume) solvents at $0.1 \mathrm{C}$, and $\mathbf{d} \mathrm{Na} / \mathrm{S} @ \mathrm{MPCF}$ cells containing $2 \mathrm{M} \mathrm{NaTFSI}$ in PC: FEC solvents with various FEC proportion and with/without Inl 3 additive at $0.1 \mathrm{C}$. The corresponding Coulombic efficiency represented by hollow symbols. e-h The FE-SEM images and optical images (shown in inset) of $\mathrm{Na}$ anodes obtained from Na/S@MPCF cells using different electrolytes after 50 cycles at $0.1 \mathrm{C}$. Scale bars are $2 \mu \mathrm{m}$ in Fig. 2e-h 
deliver an ionic conductivity of $1.95 \times 10^{-3} \mathrm{~S}^{-1} \mathrm{~cm}^{-1}$ at $25^{\circ} \mathrm{C}$, which is sufficient to meet the requirement for room-temperature $\mathrm{Na}-\mathrm{S}$ batteries. The electrochemical stability of electrolytes was evaluated using linear sweep voltammetry (LSV) on stainless steel electrodes. As shown in Fig. 2b, no peak or noticeable oxidation current is observed in the voltammogram of the $2 \mathrm{M}$ NaTFSI in PC: FEC (1:1 by volume) electrolyte up to $5.09 \mathrm{~V}$ vs. $\mathrm{Na} / \mathrm{Na}^{+}$. This implies that such electrolyte is stable up to $5.0 \mathrm{~V}$, which is obviously higher than that of $1 \mathrm{M}$ NaTFSI in PC $(4.54 \mathrm{~V})$ and $1 \mathrm{M}$ NaTFSI in PC: FEC (1: 1 by volume) $(4.95 \mathrm{~V})$. This enhanced electrochemical stability is ascribed to the strong resistance of FEC solvent to oxidation ${ }^{42}$, and the pre-formed passive layer attributed to high salt concentration ${ }^{43}$. A small peak starts at around $2.9 \mathrm{~V}$ in the voltammogram of $2 \mathrm{M}$ NaTFSI in PC: FEC with $\mathrm{InI}_{3}$ additive (Fig. 2b, inset), which can be assigned to the oxidation of $\mathrm{I}^{-}$to $\mathrm{I}_{3}{ }^{-39}$, and the electrochemical working window slightly increases to $5.20 \mathrm{~V}$. In Supplementary Fig. 8, Na/Na symmetrical cells were subject to galvanostatic cycling measurements at a current density of $0.1 \mathrm{~mA} \mathrm{~cm}^{-2}$ to investigate the compatibility of $2 \mathrm{M}$ NaTFSI in PC: FEC with $\mathrm{InI}_{3}$ electrolyte with $\mathrm{Na}$ metal anode. It shows a much smaller overpotential with negligible voltage fluctuation than the cell using $1 \mathrm{M}$ NaTFSI in PC electrolyte (shown in inset) during the $900 \mathrm{~h}$ cycles, indicating a uniform $\mathrm{Na}$ deposition with a stable electrolyte/ $\mathrm{Na}$ metal interface ${ }^{44}$.

The cycling performances of Na/S@MPCF cells using different concentrations of NaTFSI salt in PC: FEC (1: 1 by volume) as electrolytes are shown in Fig. 2c. The cycling capacities of $\mathrm{Na}$ / S@MPCF cells continuously increase with the rising salt concentration (from $680 \mathrm{mAh} \mathrm{g}^{-1}$ in $1 \mathrm{M} \mathrm{NaTFSI}$ in PC: FEC to $907 \mathrm{mAh} \mathrm{g}^{-1}$ in $2 \mathrm{M}$ NaTFSI in PC: FEC after 100 cycles at $0.1 \mathrm{C}$, more details shown in Supplementary Fig. 9), which can be ascribed to the suppression of $\mathrm{Na}$ polysulfide dissolution and inhibition of anodic dendrite formation in concentrated electrolyte ${ }^{41}$. However, the capacity gradually decreases at high salt concentrations beyond $2 \mathrm{M}$ (607 $\mathrm{mAh} \mathrm{g}^{-1}$ in $2.5 \mathrm{M}$ NaTFSI in PC: FEC after 100 cycles at $0.1 \mathrm{C}$ ) owing to excessive electrolyte viscosity (Supplementary Fig. 7). Therefore, an optimal salt concentration is set as $2 \mathrm{M}$. More remarkably, the cycling capacity of Na/S@MPCF cells consistently increased with increasing FEC proportion in $2 \mathrm{M}$ NaTFSI in PC: FEC electrolytes (from $20 \mathrm{mAh} \mathrm{g}^{-1}$ with pure PC to $814 \mathrm{mAh} \mathrm{g}^{-1}$ with PC/FEC at a volume ratio of $1: 1$ after 150 cycles at $0.1 \mathrm{C}$, Fig. 2d). This could be attributed to the FEC solvent making significant contributions towards restricting the dissolution of $\mathrm{Na}$ polysulfides (details shown in Supplementary Fig. 10) and forming a stable protective SEI on the $\mathrm{Na}$ anode (see analysis below). However, it should be noted that the increased viscosity (Supplementary Fig. 7) and decreased conductivity (Supplementary Fig. 11) in electrolytes with excessively high FEC ratio $(>50 \%)$ gives rise to a decline in reversible capacity (Supplementary Fig. 12). Therefore, the FEC proportion was optimized as $50 \%$ in this study. It is also shown in Fig. $2 \mathrm{~d}$ and Supplementary Fig. 13 that the addition of $\mathrm{InI}_{3}$ additive can significantly enhance the Coulombic efficiency and cycling stability of $\mathrm{Na}-\mathrm{S}$ batteries. The $\mathrm{Na} / 2 \mathrm{M}$ NaTFSI in PC: FEC (1:1 by volume) with $10 \mathrm{mM} \mathrm{InI}_{3} / \mathrm{S} @ \mathrm{MPCF}$ cell delivers an initial Coulombic efficiency of $79.1 \%$ and a discharge capacity of 1000 $\mathrm{mAh} \mathrm{g}^{-1}$ after 150 cycles at $0.1 \mathrm{C}$, which is much higher than the cell without $\mathrm{InI}_{3}$ additive $\left(73.8 \%\right.$ and $\left.814 \mathrm{mAh} \mathrm{g}^{-1}\right)$. As shown in the inset of Fig. $2 \mathrm{~b}, \mathrm{I}^{-}$is oxidized to $\mathrm{I}_{3}{ }^{-}$at around $2.9 \mathrm{~V}$ vs. $\mathrm{Na} / \mathrm{Na}^{+}$ during the charge process. The $\mathrm{I}_{3}{ }^{-}$subsequently reacts with $\mathrm{Na}_{2} \mathrm{~S}$ to form $\mathrm{Na}$ polysulfides (details shown in Supplementary Fig. 14):

$$
n \mathrm{Na}_{2} \mathrm{~S}+(n-1) \mathrm{I}_{3}^{-} \rightarrow 3(n-1) \mathrm{I}^{-}+\mathrm{Na}_{2} \mathrm{~S}_{n}
$$

Such reaction can effectively promote the kinetics of $\mathrm{Na}_{2} \mathrm{~S}$ transformation and prevent it from depositing on the cathode.
Furthermore, the $\mathrm{In}^{3+}$ can construct a protective In metal layer on the anode in the charge process before $\mathrm{Na}^{+}$deposition $(-2.71$ $\mathrm{V}$ vs. $\mathrm{SHE})^{45,46}$ :

$$
\mathrm{In}^{3+}+3 \mathrm{e}^{-} \rightarrow \operatorname{In}(-0.340 \mathrm{~V} v s . \mathrm{SHE})
$$

Therefore, the anodic corrosion caused by the shuttle effect can be effectively restrained. Hence, the $\mathrm{InI}_{3}$ additive contributes to the improved Coulombic efficiency and outstanding cycling performance.

Figure $2 \mathrm{e}-\mathrm{h}$ further show field emission scanning electron microscopy (FE-SEM) images of the $\mathrm{Na}$ anodes disassembled from the cells used $1 \mathrm{M}$ NaTFSI in PC (cycling performance shown in Supplementary Fig. 15), 1 M NaTFSI in PC: FEC (1:1 by volume), $2 \mathrm{M}$ NaTFSI in PC: FEC (1:1 by volume) and $2 \mathrm{M}$ NaTFSI in PC: FEC (1:1 by volume) with $10 \mathrm{mM} \mathrm{InI}_{3}$ electrolytes after 100 cycles at $0.1 \mathrm{C}$. It can be clearly seen that massive dendrite structures and holes appear on the surface of $\mathrm{Na}$ electrodes obtained from the cells using $1 \mathrm{M}$ NaTFSI in PC electrolyte (Fig. 2e and the cross-sectional FE-SEM image in Supplementary Fig. 16), and the sulfur content on this anode is as high as $11.8 \mathrm{wt} \%$ (Supplementary Fig. 17). With the addition of high-concentration salt, FEC solvent and $\mathrm{InI}_{3}$ additive, as expected, the surfaces of $\mathrm{Na}$ anodes become smoother and dendrite growth is dramatically inhibited. The sulfur content on the anode of the cell using $2 \mathrm{M}$ NaTFSI in PC: FEC with $\mathrm{InI}_{3}$ is as low as $2.9 \mathrm{wt} \%$ (Fig. 2h), demonstrating a significant inhibition of polysulfide shuttling.

X-ray photoelectron spectroscopy (XPS) measurements were performed to investigate the surface components of these $\mathrm{Na}$ anodes. As shown in Fig. 3a, the peaks at about 288.5, 286.7, and $284.8 \mathrm{eV}$ in $\mathrm{C} 1 \mathrm{~s}$ can be assigned to $\mathrm{O}-\mathrm{C}=\mathrm{O}, \mathrm{C}-\mathrm{O}$, and $\mathrm{C}-\mathrm{C}$, respectively. Peaks at $686.6 \mathrm{eV}$ and $683.8 \mathrm{eV}$ in $\mathrm{F} 1 \mathrm{~s}$ are related to C-F in TFSI $^{-}$and sodium fluoride $(\mathrm{NaF})$, and 170,161 , and $159.5 \mathrm{eV}$ in $\mathrm{S} 2 \mathrm{p}$ correspond to $\mathrm{O}=\mathrm{S}=\mathrm{O}$ on $\mathrm{TFSI}^{-}, \mathrm{S}_{2}{ }^{2-}$, and $\mathrm{S}^{2-}$ derived from $\mathrm{Na}_{2} \mathrm{~S}_{2}$ and $\mathrm{Na}_{2} \mathrm{~S}$, respectively. Peaks corresponding to $\mathrm{SO}_{4}^{2-}$ at about $168 \mathrm{eV}, \mathrm{SO}_{3}^{2-}$ at about $166.5 \mathrm{eV}, \mathrm{S}_{8}$ at about $163.5 \mathrm{eV}\left(\mathrm{S} 2 \mathrm{p}_{3 / 2}\right)$, and $164.7 \mathrm{eV}\left(\mathrm{S} 2 \mathrm{p}_{1 / 2}\right)$ are also observed in $\mathrm{S}$ $2 \mathrm{p}$ spectra ${ }^{47,48}$. There is a general tendency that the $\mathrm{C}-\mathrm{F}$ bond in $\mathrm{F} 1 \mathrm{~s}$ at about $688 \mathrm{eV}^{49}$ and $\mathrm{C} 1 \mathrm{~s}$ at about $292.5 \mathrm{eV}^{50}$ become stronger with increasing FEC proportion in electrolytes along with some polycarbonates $\left(\operatorname{poly}\left(\mathrm{CO}_{3}\right)\right)$ appearing at $290-291$ $\mathrm{eV}^{51}$ in the $\mathrm{C} 1 \mathrm{~s}$ spectra. The peak intensity of $\mathrm{NaF}$ in $\mathrm{F} 1 \mathrm{~s}$ also gradually increases with increasing FEC proportion and salt concentration, which verifies the formation of a F-rich SEI layer on the anode surface. This can be further confirmed by the elemental mapping in Supplementary Fig. 17, Such F-containing components in the SEI are known to have high mechanical strength (e.g., NaF possesses a shear modulus of $31.4 \mathrm{GPa}$, more than 10 times higher than that of $\mathrm{Na}_{\text {metal }}{ }^{12}$ ), which enables the SEI layer to suppress the dendritic growth of $\mathrm{Na}$ metal. The $\mathrm{S}^{2-}$ and $\mathrm{S}_{2}{ }^{2-}$ peaks in $\mathrm{S} 2 \mathrm{p}$ spectra sharply decline when FEC proportion or salt concentration is increased. This is clear evidence that the solubility of $\mathrm{Na}$ polysulfides in FEC or in concentrated electrolyte is so low that only trace amounts of $\mathrm{Na}_{2} \mathrm{~S}$ and $\mathrm{Na}_{2} \mathrm{~S}_{2}$ are depositing on the $\mathrm{Na}$ anode. Moreover, the $\mathrm{Na}$ anode of the cell using $2 \mathrm{M}$ NaTFSI in PC: FEC with $10 \mathrm{mM} \mathrm{InI}_{3}$ additive electrolyte exhibits peaks of In $3 \mathrm{~d}$ at about $457 \mathrm{eV}$ and $445 \mathrm{eV}^{45}$ with a In content of $4.8 \mathrm{wt} \%$ (Supplementary Fig. 17), meanwhile the peaks of $\mathrm{S}^{2-}$ and $\mathrm{S}_{2}{ }^{2-}$ peaks in $\mathrm{S} 2 \mathrm{p}$ spectra nearly disappear, which indicates that the In layer effectively inhibits shuttle effect, as well as $\mathrm{I}^{-} / \mathrm{I}_{3}^{-}$scavenges the polysulfides at the cathode. Visual observations on the same amount of sulfur powder together with a $\mathrm{Na}$ electrode soaked in different electrolytes were performed to identify the formation and 
a
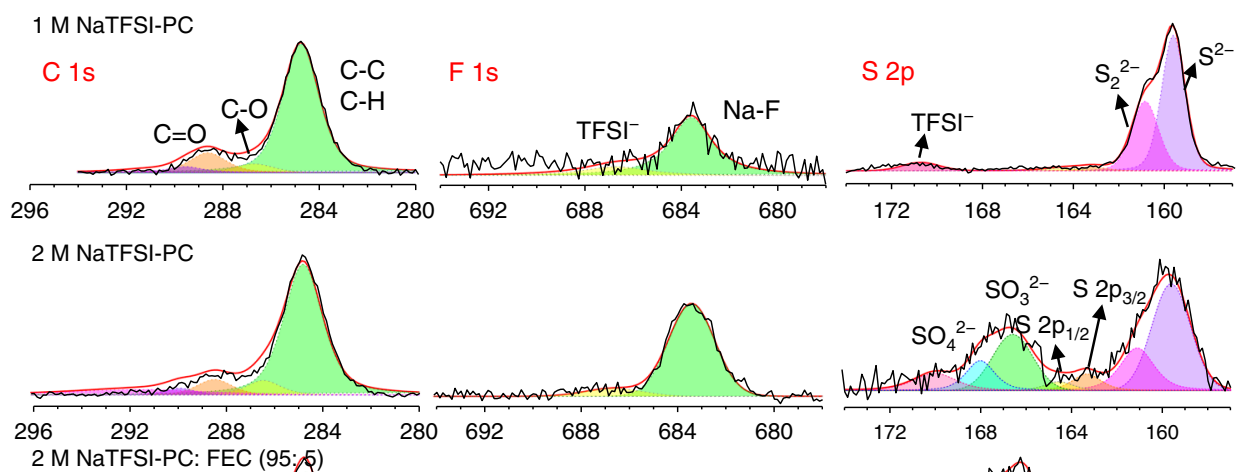

2 M NaTFSI-PC: FEC (95:\$)

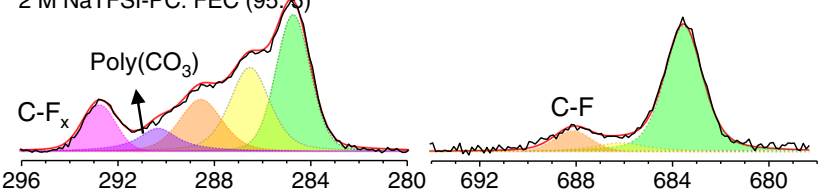

2 M NaTFSI-PC: FEC (1: 1)
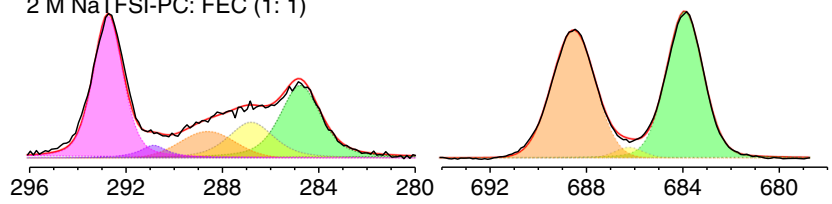

2 M NaTFSI-PC: FEC (1: 1) + $\operatorname{lnI}_{3}$
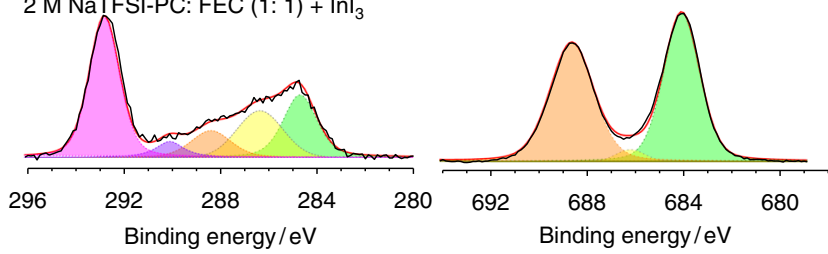

b

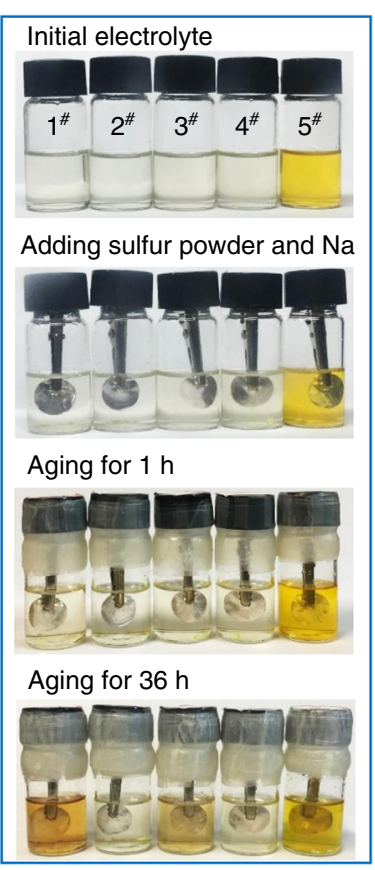

Fig. 3 Characterization of polysulfides formation in different electrolyte systems. a XPS spectra of the Na metals from Na/S@MPCF cells using different electrolytes after 50 cycles at 0.1 C; b Visual observation of Na polysulfides formation in five electrolyte samples (1\#:1 M NaTFSI in PC; $2 \#: 1 \mathrm{M} \mathrm{NaTFSI} \mathrm{in}$ PC: FEC (1:1 by volume); 3\#: 2 M NaTFSI in PC; 4\#: 2 M NaTFSI in PC: FEC (1:1 by volume); 5\#: 2 M NaTFSI in PC: FEC (1:1 by volume) with 10 mM Inl 3 ) along with aging time at $60^{\circ} \mathrm{C}$, The same amounts of sulfur $(5 \mathrm{mg})$ and $\mathrm{Na}$ metal foils were added into the electrolytes to simulate the self-discharge processes

diffusion of $\mathrm{Na}$ polysulfides by observing the color change directly. The electrolyte $1 \#$ (1 M NaTFSI in PC) becomes dark in color after aging at $60{ }^{\circ} \mathrm{C}$ for $36 \mathrm{~h}$ (Fig. 3b). This conspicuous color change demonstrates that the sulfur powder continuously dissolves in the simplistic electrolyte and electrochemically reacts with $\mathrm{Na}$ metal to form highly soluble polysulfides with dark colors (corresponding to a self-discharge phenomenon in cells) ${ }^{52}$. However, the 2\# (1 M NaTFSI in PC: FEC), 3\# (2 M NaTFSI in PC), and 4\# (2 M NaTFSI in PC: FEC) electrolytes maintain transparent or light yellow after aging due to the low solubility of $\mathrm{Na}$ polysulfides in FEC solvent or high salt concentration solution. The $5 \#$ electrolyte, $2 \mathrm{M}$ NaTFSI in PC: FEC (1:1 by volume) with $10 \mathrm{mM} \mathrm{InI}_{3}$, maintains a yellow color from the $\mathrm{InI}_{3}$ additive during the aging test. As further verified by ultraviolet (UV)-visible (Vis) spectra in Supplementary Fig. 18, $\mathrm{Na}$ polysulfides were barely formed in this electrolyte. In conclusion, it is the synergistic effect of FEC, highly concentrated salt and $\mathrm{InI}_{3}$ additive that remarkably improves the electrochemical performance of $\mathrm{Na}-\mathrm{S}$ batteries via an effective suppression of $\mathrm{Na}$ polysulfides diffusion, an enhanced $\mathrm{Na}_{2} \mathrm{~S}$ conversion and an efficient construction of protective layer on $\mathrm{Na}$ anode.

To investigate the chemistry of $\mathrm{Na} / 2 \mathrm{M}$ NaTFSI in PC: FEC (1:1 by volume) with $10 \mathrm{mM} \mathrm{InI}_{3} / \mathrm{S} @ M P C F$ in a battery, ex-situ Raman spectra were measured to track the changes of sulfur species during the discharge/charge processes. As shown in Fig. $4 \mathrm{a}$, when the initial cathode is discharged to $2.7 \mathrm{~V}$, a sharp peak appears at about $746 \mathrm{~cm}^{-1}$ due to the formation of $\mathrm{Na}_{2} \mathrm{~S}_{x}$ $(x=4-8)^{53}$, which gradually weakens during following discharge process because of its conversion to $\mathrm{Na}_{2} \mathrm{~S}$ and $\mathrm{Na}_{2} \mathrm{~S}_{2}$. Meanwhile, after discharging to $1.6 \mathrm{~V}$, the Raman spectra show a peak at about $484 \mathrm{~cm}^{-1}$ related to $\mathrm{Na}_{2} \mathrm{~S}_{4}{ }^{54}$ along with the disappearance of the peaks at $80,156,220$ and $475 \mathrm{~cm}^{-1}$ belonging to $\mathrm{S}_{8}{ }^{55}$. The peak of $\mathrm{Na}_{2} \mathrm{~S}$ at $188 \mathrm{~cm}^{-1}$ and $\mathrm{Na}_{2} \mathrm{~S}_{2}$ at $430 \mathrm{~cm}^{-1}$ are readily formed at $1.2 \mathrm{~V}^{55}$, and persistently exist during following charge and discharge process, demonstrating that the solid $\mathrm{Na}_{2} \mathrm{~S}$ formed in the initial discharge process could not be completely oxidized in the following cycles due to poor kinetics during the transitions of solid-state short-chain polysulfides or $\mathrm{Na}_{2} \mathrm{~S}^{37}$. The subsequent charge process as an opposite process shows the peak of $\mathrm{Na}_{2} \mathrm{~S}_{x}$ $(x=4-8)$ arising from $1.0 \mathrm{~V}$ and gradually increasing until $1.8 \mathrm{~V}$. The peaks of $\mathrm{S}_{8}$ appear at $2.2 \mathrm{~V}$ in this charge process. It is noteworthy that the peak of $\mathrm{Na}_{2} \mathrm{~S}_{x}(x=4-8)$ retains its intensity at $2.8 \mathrm{~V}$, indicating the transformation from $\mathrm{Na}_{2} \mathrm{~S}$ to $\mathrm{Na}_{2} \mathrm{~S}_{x}$ in the presence of $\mathrm{I}_{3}^{-}$as mentioned before.

The cyclic voltammetry (CV) of $\mathrm{Na} / 2 \mathrm{M}$ NaTFSI in PC: FEC (1:1 by volume) with $10 \mathrm{mM} \mathrm{InI}_{3} / \mathrm{S} @ M P C F$ cell is shown in Fig. 4b. During the initial cathodic scan, the current slope starts at around $2.1 \mathrm{~V}$ vs. $\mathrm{Na} / \mathrm{Na}^{+}$, corresponding to the solid-liquid transition from sulfur to dissolved $\mathrm{Na}_{2} \mathrm{~S}_{x}(x=4-8)$, and the peak at $1.2-0.8 \mathrm{~V}$ is related to the formation of $\mathrm{Na}_{2} \mathrm{~S}$ and $\mathrm{Na}_{2} \mathrm{~S}_{2}$ according to the Raman spectra. The peaks of $\mathrm{Na}_{2} \mathrm{~S}$ and $\mathrm{Na}_{2} \mathrm{~S}_{2}$ show relatively low repeatability in the following cathodic sweep, 
a

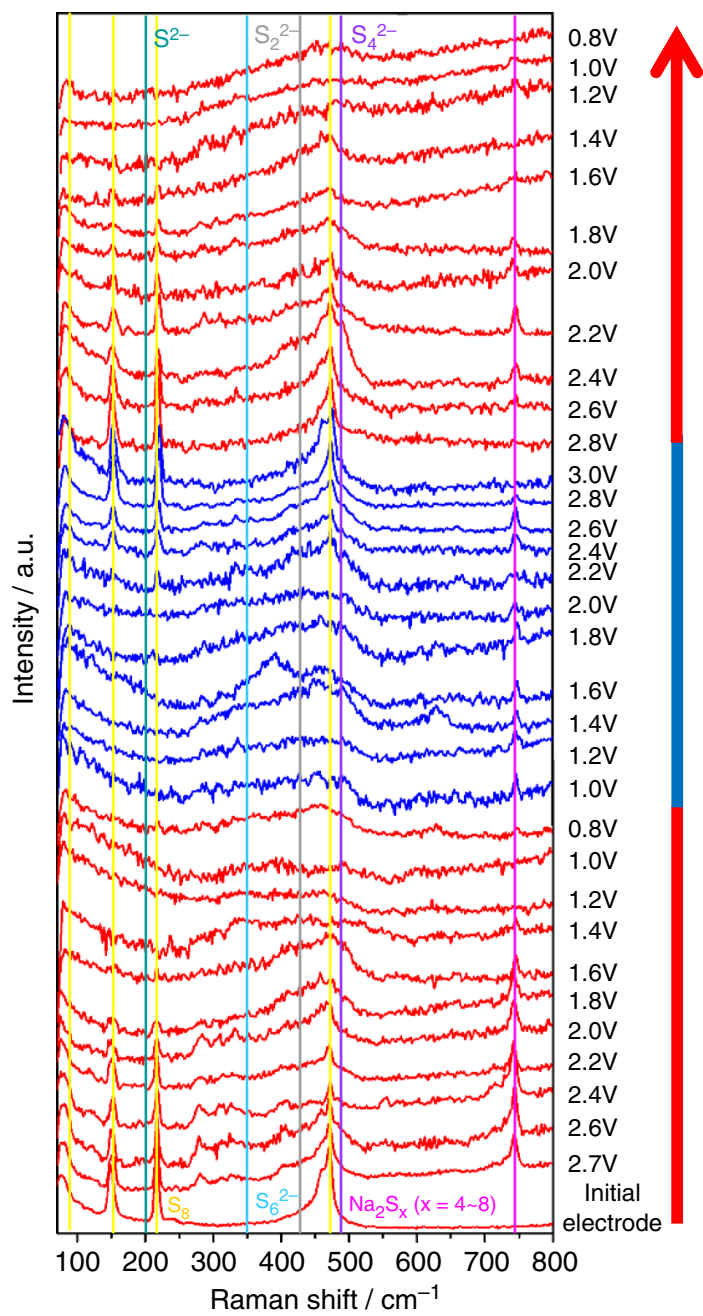

d

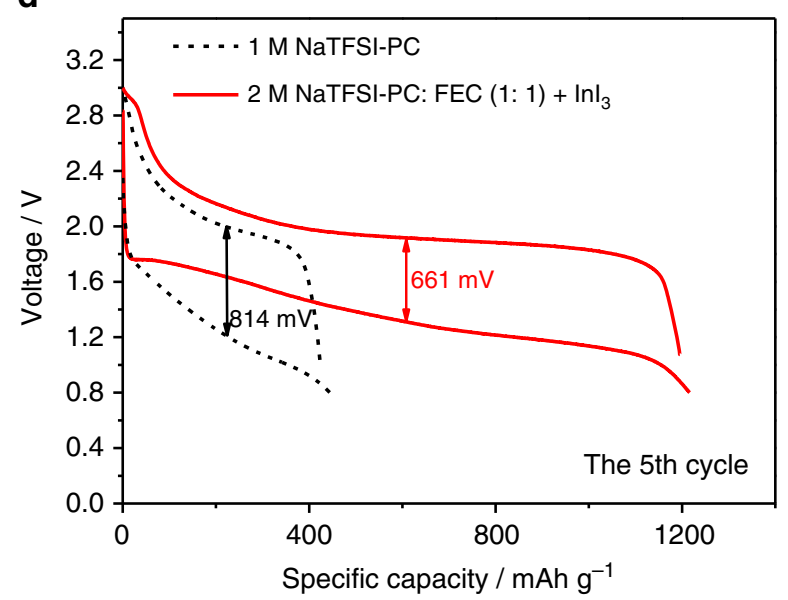

b

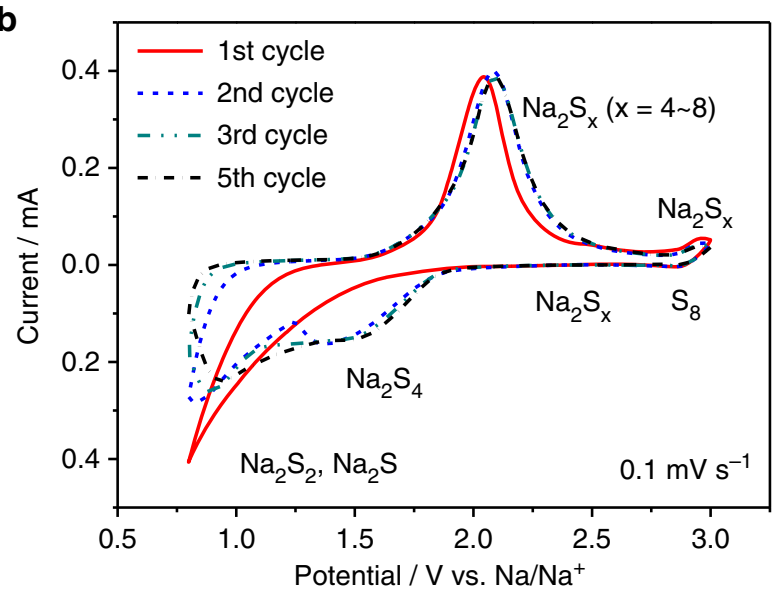

c

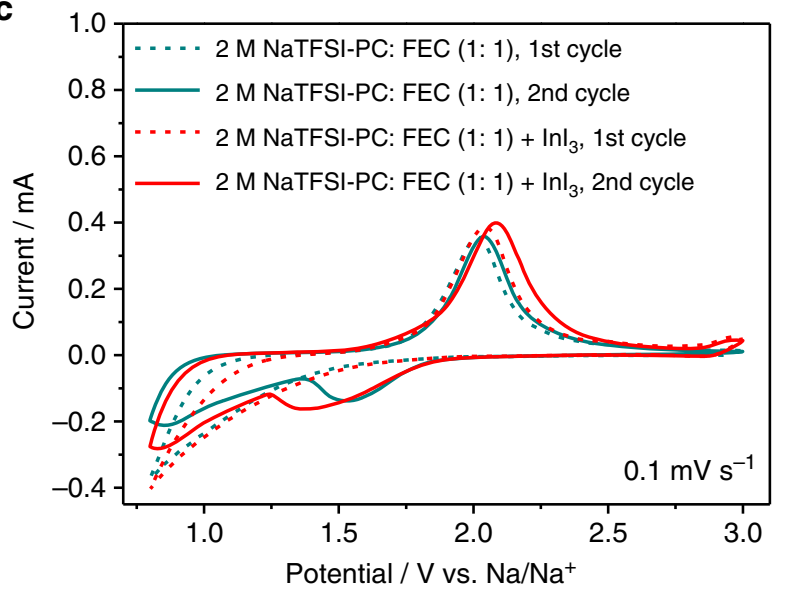

e

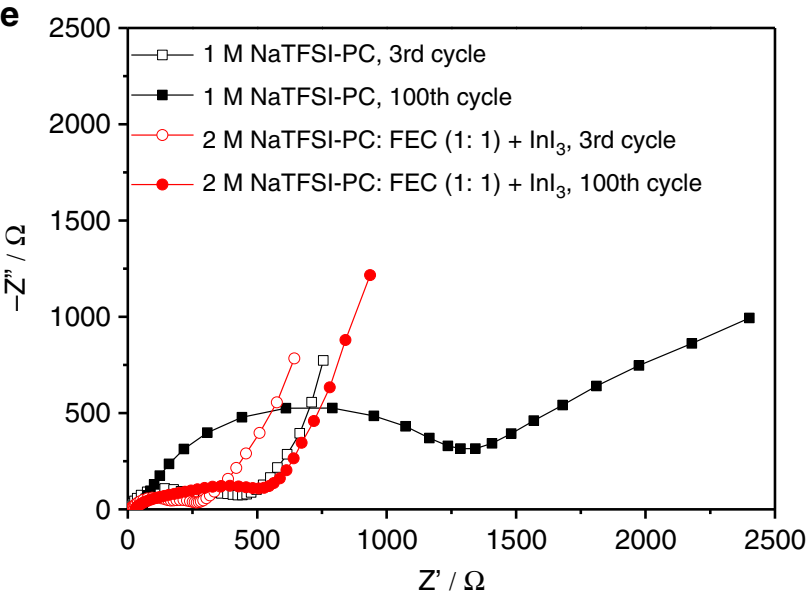

Fig. 4 Electrochemical behavior of different Na-S battery systems. a Ex-situ Raman spectra of the S@MPCF electrodes obtained from Na/2 M NaTFSI in PC: FEC with $10 \mathrm{mM} \mathrm{Inl} / 3 / \mathrm{S} @ M P C F$ cells at different charge/discharge potentials; b The 1st, 2nd, 3rd, and 5th CV cycles of Na/2 M NaTFSI in PC: FEC with Inl 3 / S@MPCF cell at $0.1 \mathrm{mV} \mathrm{s}^{-1}$; c CV curves of $\mathrm{Na} / \mathrm{S} @ M P C F$ cells using $2 \mathrm{M} \mathrm{NaTFSI}$ in PC: FEC and $2 \mathrm{M} \mathrm{NaTFSI} \mathrm{in} \mathrm{PC:} \mathrm{FEC} \mathrm{with} \mathrm{Inl} \mathrm{e}_{3}$ electrolytes at $0.1 \mathrm{mV} \mathrm{s}^{-1}$; d The 5th charge/discharge profiles of Na/S@MPCF cells using 1 M NaTFSI in PC and 2 M NaTFSI in PC: FEC with Inl 3 electrolytes at $0.1 \mathrm{C}$; e Nyquist plots of $\mathrm{Na}$ /S@MPCF cells using 1M NaTFSI in PC and 2 M NaTFSI in PC: FEC with Inl 3 electrolytes after three cycles and 100 cycles at $0.1 \mathrm{C}$, measured in the half charged state

indicating their incomplete conversion. For the anodic scan, a repeatable peak at around $2.1 \mathrm{~V}$ presents over all the cycles, corresponding to the transformation of short-chain sodium sulfides to long-chain polysulfides ${ }^{8}$. A small anodic peak is clearly observed at about $2.9 \mathrm{~V}$ in the cell with $\mathrm{InI}_{3}$ additive, which corresponds to the conversion from $\mathrm{I}^{-}$to $\mathrm{I}_{3}{ }^{-}$. The addition of $\mathrm{InI}_{3}$ additive greatly reduces the irreversibility of the $\mathrm{Na}_{2} \mathrm{~S}$ and $\mathrm{Na}_{2} \mathrm{~S}_{2}$ peaks compared to the cell without $\mathrm{InI}_{3}$ additive (Fig. 4c), 
which is well consistent with the improved initial Coulombic efficiency in Fig. 2d. The subsequent 2-5th CV curves with two evolving cathodic peaks at around $1.5 \mathrm{~V}\left(\mathrm{Na}_{2} \mathrm{~S}_{x}(x=4-8)\right)$ and $0.8 \mathrm{~V}\left(\mathrm{Na}_{2} \mathrm{~S}\right.$ and $\left.\mathrm{Na}_{2} \mathrm{~S}_{2}\right)$ are highly repeatable, indicating that the cathode and anode are highly reversible in the $2 \mathrm{M}$ NaTFSI-PC: FEC (1:1 by volume) with $\mathrm{InI}_{3}$ electrolyte system.

Electrochemical mechanism discussion. Supplementary Fig. 19 shows the representative charge/discharge profiles of $\mathrm{Na} / 2 \mathrm{M}$ NaTFSI in PC: FEC (1:1 by volume) with $10 \mathrm{mM} \mathrm{InI}_{3} / \mathrm{S} @ M P C F$ cell at $0.1 \mathrm{C}$. It is seen that a sloping plateau from 1.8 to $1.5 \mathrm{~V}$ and a long plateau in the range of 1.5 to $1.0 \mathrm{~V}$ appears in the initial discharge process, which is consistent with the CV curves. The large initial discharge capacity $\left(1635 \mathrm{mAh}^{-1}\right)$ indicates a high utilization of sulfur in the cathode. It is worth noting that the lowvoltage plateau cannot be fully reversed in the following cycles caused by the incomplete $\mathrm{Na}_{2} \mathrm{~S}$ conversion. However, the initial Coulombic efficiency of $2 \mathrm{M}$ NaTFSI in PC: FEC with $\mathrm{InI}_{3}$ electrolyte $(79.1 \%)$ is significantly higher than that of $1 \mathrm{M}$ NaTFSI in $\mathrm{PC}(68.9 \%)$ due to the effect of $\mathrm{InI}_{3}$ additive, corresponding to the CV curves of Supplementary Fig. 20. Furthermore, the charge/ discharge potential gap of the cell used $2 \mathrm{M}$ NaTFSI in PC: FEC with $\mathrm{InI}_{3}$ electrolyte at $0.1 \mathrm{C}(\sim 661 \mathrm{mV})$ is much smaller than that using $1 \mathrm{M}$ NaTFSI in PC electrolyte $(\sim 814 \mathrm{mV})$ (Fig. $4 \mathrm{~d})$. The reduced potential gap suggests that the $2 \mathrm{M} \mathrm{NaTFSI}$ in PC: FEC with $\mathrm{InI}_{3}$ electrolyte significantly decreases the polarization of $\mathrm{Na}-\mathrm{S}$ batteries. Electrochemical impedance spectroscopy (EIS) was measured to evaluate the interfacial behavior and reversibility of cells using such optimized electrolyte. Figure 4e shows the EIS results of the $\mathrm{Na}-\mathrm{S}$ cells using different electrolytes after different cycles. Such EIS spectra are simulated via an equivalent circuit shown in Supplementary Fig. 21, and the simulation results are summarized in Supplementary Table 3. It is seen that the interfacial resistance $\left(R_{\mathrm{f}}\right)$ of the cell employed $1 \mathrm{M}$ NaTFSI in PC electrolyte sharply increases after 100 cycles compared with the 3rd cycle (from $156.2 \Omega$ to $789.2 \Omega$ ) due to the unstable SEI film caused by the shuttle effect in the cathode and sodium dendrites on the anode as illustrated above. The greatly increased charge transfer resistance $\left(R_{\mathrm{ct}}\right.$, from $372.3 \Omega$ to $856.2 \Omega$ ) can be interpreted by the irreversibility of electrically insulating $\mathrm{Na}_{2} \mathrm{~S}$, which deposited on the surface of electrodes and acts as a barrier for the electron/ion transport. In sharp contrast, the value of $R_{\mathrm{ct}}$ and $R_{\mathrm{f}}$ in the cell using $2 \mathrm{M}$ NaTFSI in PC: FEC with $\mathrm{InI}_{3}$ electrolyte are much smaller, and stay almost unchanged during cycling. This indicates an increased conversion degree of $\mathrm{Na}_{2} \mathrm{~S}$, a suppression of shuttle effect and stability of the electrode/electrolyte interface, and contributes to the dramatically enhanced performance shown in Fig. 2d.

First-principle calculations of the interactions. First-principle calculations were employed to further analyze the interaction between $\mathrm{Na}$ polysulfide/ $\mathrm{Na}_{2} \mathrm{~S}$ and cathode components as well as electrolyte solvents. As shown in Fig. 5a, the binding energy between $\mathrm{Na}_{2} \mathrm{~S}_{6}$ as a representative of $\mathrm{Na}$ polysulfides and $\mathrm{PC}$ is calculated to be $-1.57 \mathrm{eV}$, which is remarkably stronger than that of $\mathrm{CMC}^{-}$ion- $\mathrm{Na}_{2} \mathrm{~S}_{6}(-1.26 \mathrm{eV}$, Fig. $5 \mathrm{~g})$, graphitized carbon matrix $-\mathrm{Na}_{2} \mathrm{~S}_{6}(-1.46 \mathrm{eV}$, Fig. 5e), and the formation energy of $\mathrm{Na}_{4} \mathrm{~S}_{12}$ clusters $(-1.29 \mathrm{eV}$, Fig. $5 \mathrm{i})$. As a result, $\mathrm{Na}_{2} \mathrm{~S}_{6}$ tends to dissolve in the PC-based electrolyte. In sharp contrast, the binding energy between $\mathrm{Na}_{2} \mathrm{~S}_{6}$ and FEC is as low as $-1.22 \mathrm{eV}$ (Fig. 5c), which is obviously lower than that of $\mathrm{CMC}^{-}$ion- $\mathrm{Na}_{2} \mathrm{~S}_{6}$ and graphitized carbon matrix- $\mathrm{Na}_{2} \mathrm{~S}_{6}$. Therefore, in this case, $\mathrm{Na}_{2} \mathrm{~S}_{6}$ molecules preferentially adhere to the cathode surface rather than dissolves into the FEC-based electrolyte, which is well coincident with the experimental results (Fig. 3b). It is also seen that the formation energy of $\mathrm{Na}_{4} \mathrm{~S}_{2}$ cluster $(-2.11 \mathrm{eV}$, Fig. $5 \mathrm{j})$ is much higher than the binding energies of $\mathrm{Na}_{2} \mathrm{~S}$ with the solvents $\left(-1.36 \mathrm{eV}\right.$ for $\mathrm{PC}-\mathrm{Na}_{2} \mathrm{~S}$ (Fig. 5b) and $-1.09 \mathrm{eV}$ for $\mathrm{FEC}-\mathrm{Na}_{2} \mathrm{~S}$ (Fig. 5d) and cathode components $\left(-1.16 \mathrm{eV}\right.$ for $\mathrm{CMC}^{-}-\mathrm{Na}_{2} \mathrm{~S}$ (Fig. 5h) and $-1.19 \mathrm{eV}$ for graphitized carbon- $\mathrm{Na}_{2} \mathrm{~S}$ (Fig. 5f). This clearly confirms that $\mathrm{Na}_{2} \mathrm{~S}$ tends to agglomerate into a solid network in the electrode, which leads to the difficulty to be transferred to Na polysulfides as illustrated in Fig. 4a. The above theoretical results support an in-depth understanding of $\mathrm{Na}$ polysulfide shuttle mechanism in carbonate-based electrolytes.

Electrochemical performance evaluation. Figure $6 \mathrm{a}$ shows the long-term cycling performance of the $\mathrm{Na} / 2 \mathrm{M}$ NaTFSI in PC: FEC (1:1 by volume) with $10 \mathrm{mM} \mathrm{InI}_{3} / \mathrm{S} @ \mathrm{MPCF}$ cells at 0.5 and $1 \mathrm{C}$, respectively (the cycling performance at $0.1 \mathrm{C}$ is exhibited in Supplementary Fig. 22). The initial irreversible conversion of $\mathrm{Na}_{2} \mathrm{~S}$ results in an initial Coulombic efficiency of $79.1 \%$ at $0.1 \mathrm{C}$, $71.9 \%$ at $0.5 \mathrm{C}$ and $61.6 \%$ at $1 \mathrm{C}$. During the following cycles, high Coulombic efficiency (98.5\%-100.4\%) and limited capacity decay were achieved. After 200 cycles at $0.1 \mathrm{C}$, the discharge capacity of $\mathrm{Na} / 2 \mathrm{M}$ NaTFSI in PC: FEC with $\mathrm{InI}_{3} / \mathrm{S} @ \mathrm{MPCF}$ cell is $927 \mathrm{mAh} \mathrm{g}^{-1}$ with a capacity retention of $77.7 \%$ except for the initial cycle (Supplementary Fig. 22). Considering a mid-value discharge voltage of $\sim 1.4 \mathrm{~V}$, the corresponding energy density is around $1477 \mathrm{Wh} \mathrm{kg}^{-1}$ and $886 \mathrm{Wh} \mathrm{kg}^{-1}$ calculated based on the mass of sulfur and S@C composite, respectively. Furthermore, after about 500 cycles at 0.5 and $1 \mathrm{C}$, discharge capacities of $648 \mathrm{mAh} \mathrm{g}^{-1}$ and $581 \mathrm{mAh} \mathrm{g}^{-1}$ remained, respectively, which demonstrates an outstanding long cycling stability. The rate performances of the $\mathrm{Na} / 2 \mathrm{M}$ NaTFSI in PC: FEC with $\mathrm{InI}_{3} / \mathrm{S} @ \mathrm{MPCF}$ cells are shown in Fig. 6b, while the corresponding discharge/charge curves are presented in Supplementary Fig. 23. The Na/2 M NaTFSI in PC: FEC with $\mathrm{InI}_{3} / \mathrm{S} @ \mathrm{MPCF}$ cell delivers specific charge capacities of $1170 \mathrm{mAh} \mathrm{g}^{-1}, 1107 \mathrm{mAh} \mathrm{g}^{-1}, 984 \mathrm{mAh} \mathrm{g}^{-1}, 867 \mathrm{mAh} \mathrm{g}^{-1}$, and $699 \mathrm{mAh} \mathrm{g}^{-1}$ at $0.1,0.2,0.5,1$, and $2 \mathrm{C}$, respectively, which are much higher than the cell using $1 \mathrm{M}$ NaTFSI in PC electrolyte. Furthermore, the capacity of the Na/2 M NaTFSI in PC: FEC with $\mathrm{InI}_{3} / \mathrm{S} @ \mathrm{MPCF}$ cell successfully recovers to $1140 \mathrm{mAh} \mathrm{g}^{-1}(97.4 \%$ of that in the 5th cycle) when the current density is switched back to $0.1 \mathrm{C}$, reflecting that this novel $\mathrm{Na}-\mathrm{S}$ battery system is robust and highly stable. The cycling performances of the $\mathrm{Na} / 2 \mathrm{M}$ NaTFSI in PC: FEC with $10 \mathrm{mM} \mathrm{InI}_{3} / \mathrm{S} @ \mathrm{MPCF}$ cells with high sulfur loadings were further investigated. As shown in Fig. 6c, capacities of $1134 \mathrm{mAh} \mathrm{g}^{-1}, 1038 \mathrm{mAh} \mathrm{g}^{-1}, 1007 \mathrm{mAh} \mathrm{g}^{-1}, 354$ $\mathrm{mAh} \mathrm{g}^{-1}$, and $301 \mathrm{mAh} \mathrm{g}^{-1}$ are successfully retained after 50 cycles at $0.1 \mathrm{C}$ with sulfur loadings of $0.35,1.24,1.57,4.27$ and $4.64 \mathrm{mg} \mathrm{cm}^{-2}$, respectively, which meets the requirement of practical applications. This new electrolyte also shows excellent cycling performance in $\mathrm{Na}-\mathrm{S}$ cells using other S@porous carbon composite electrodes (such as S@CMK-3 shown in Supplementary Fig. 24a).

As shown in Fig. 6d, the electrochemical performance of the $\mathrm{Na} / 2 \mathrm{M}$ NaTFSI in PC: FEC (1:1 by volume) with $10 \mathrm{mM} \mathrm{InI}_{3} /$ S@MPCF cells in this work is superior to most previously reported $\mathrm{Na}-\mathrm{S}$ cells. As an overview of the state-of-the-art, Fig. $6 \mathrm{e}$ shows a performance comparison of the as-developed $\mathrm{Na}-\mathrm{S}$ batteries with other previously reported $\mathrm{Li}$ and $\mathrm{Na}$ battery systems. In most cases, the practical specific capacity and energy density (based on the mass of cathodic active material only) for $\mathrm{Na}$ batteries is less than $900 \mathrm{mAh} \mathrm{g}^{-1}$ and $1100 \mathrm{Wh} \mathrm{kg}^{-1}$ (specially, $\quad<500 \mathrm{mAh} \mathrm{g}^{-1}$ and $<900 \mathrm{Wh} \mathrm{kg}^{-1}$ for hightemperature $\mathrm{Na}-\mathrm{S}$ batteries $^{7}$ ). The practical specific capacity and energy density of the room-temperature $\mathrm{Na}-\mathrm{S}$ battery in this work not only surpass these $\mathrm{Na}$ battery systems, but also exceed the traditional lithium-ion battery systems using cathode 
a

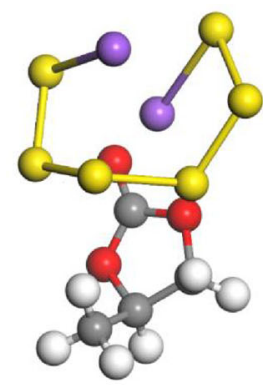

$\mathrm{PC}-\mathrm{Na}_{2} \mathrm{~S}_{6} E_{\text {bind }}=-1.57 \mathrm{eV}$

e

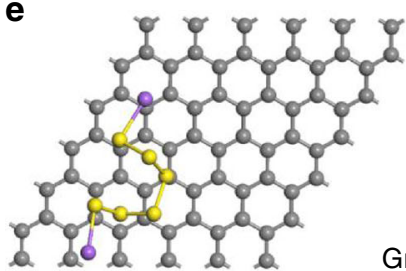

Graphite $-\mathrm{Na}_{2} \mathrm{~S}_{6} E_{\text {bind }}=-1.46 \mathrm{eV}$

g

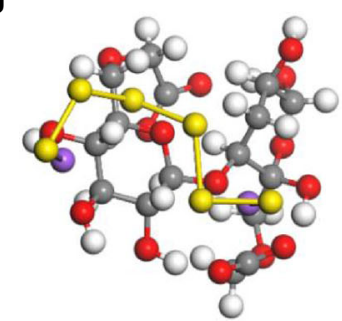

$\mathrm{CMC}^{-}-\mathrm{Na}_{2} \mathrm{~S}_{6} E_{\text {bind }}=-1.26 \mathrm{eV}$ b

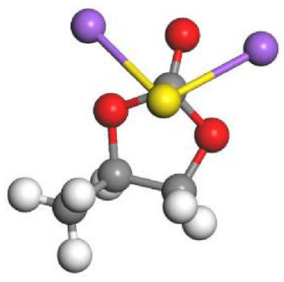

$\mathrm{PC}-\mathrm{Na}_{2} \mathrm{~S} \quad E_{\text {bind }}=-1.36 \mathrm{eV}$

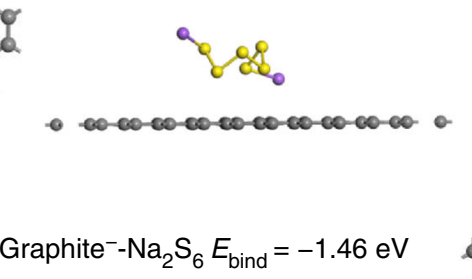

h

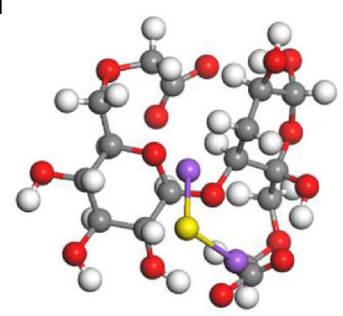

$\mathrm{CMC}^{-}-\mathrm{Na}_{2} \mathrm{~S} \quad E_{\text {bind }}=-1.16 \mathrm{eV}$
C

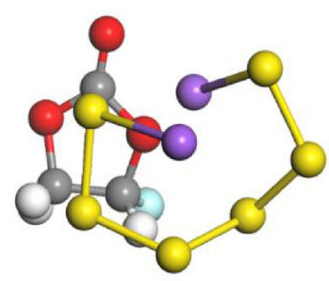

$\mathrm{FEC}-\mathrm{Na}_{2} \mathrm{~S}_{6} E_{\text {bind }}=-1.22 \mathrm{eV}$ d

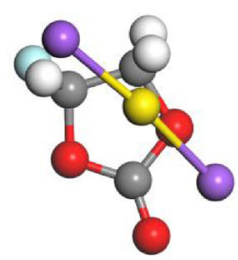

FEC- $-\mathrm{Na}_{2} S \quad E_{\text {bind }}=-1.09 \mathrm{eV}$

f

i

i
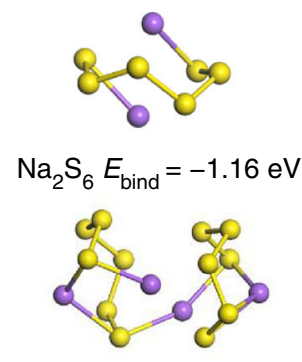

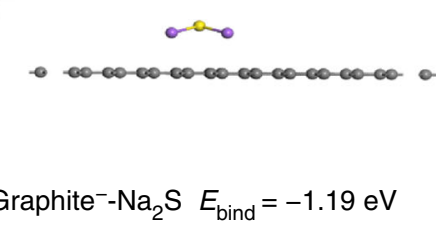

j

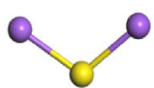

$\mathrm{Na}_{2} \mathrm{~S} E_{\text {bind }}=-1.02 \mathrm{eV}$

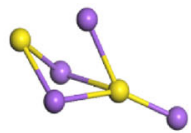

$\mathrm{Na}_{4} \mathrm{~S}_{2} E_{\text {bind }}=-2.11 \mathrm{eV}$

Fig. 5 First-principle simulations. a-d Calculated binding energies of a $\mathrm{Na}_{2} \mathrm{~S}_{6}$ and $\mathbf{b} \mathrm{Na}_{2} \mathrm{~S}$ with $\mathrm{PC}$ solvent, and $\mathbf{c} \mathrm{Na}_{2} \mathrm{~S}_{6}$ and $\mathbf{d} \mathrm{Na}_{2} \mathrm{~S}$ with $\mathrm{FEC}$ solvent; e, $\mathbf{f}$ Binding energies of $\mathbf{e} \mathrm{Na}_{2} \mathrm{~S}_{6}$ and $\mathbf{f} \mathrm{Na}_{2} \mathrm{~S}$ on graphitized carbon from top view (left) and side view (right); $\mathbf{g}, \mathbf{h}$ Binding energies of $\mathbf{g} \mathrm{Na}_{2} \mathrm{~S}_{6}$ and $\mathbf{h} \mathrm{Na}_{2} \mathrm{~S}$ with $\mathrm{CMC}^{-}$ion; $\mathbf{i}$, $\mathbf{j}$ Binding energies of the most stable $\mathbf{i} \mathrm{Na}_{2} \mathrm{~S}_{6}$ molecular/ $\mathrm{Na}_{4} \mathrm{~S}_{12}$ cluster, and $\mathbf{j} \mathrm{Na}_{2} \mathrm{~S}$ molecular/ $\mathrm{Na}_{4} \mathrm{~S}_{2}$ cluster. Yellow, purple, gray, white, red and blue balls represent sulfur, sodium, carbon, hydrogen, oxygen and fluorine atoms, respectively

materials such as lithium iron phosphate (LFP), lithium manganese oxide (LMO), and lithium cobalt oxide (LCO).

\section{Discussion}

In summary, we discovered that a multifunctional electrolyte containing $2 \mathrm{M}$ NaTFSI in PC: FEC (1:1 by volume) co-solvents with $\mathrm{InI}_{3}$ additive could greatly enhance the reversible capacity and cyclability of room-temperature $\mathrm{Na}-\mathrm{S}$ batteries. The high salt concentration in this electrolyte effectively reduces the solubility of the Na polysulfides and simultaneously stabilizes the $\mathrm{Na}$ anode. The FEC solvent not only possesses a low binding energy with $\mathrm{Na}$ polysulfides, which successfully enables polysulfides to remain in the cathode instead of dissolving into electrolyte, but also benefits the formation of a stable F-rich SEI film on the Na metal surface upon cycling. The $\mathrm{InI}_{3}$ additive acts as redox mediator to greatly improve the Coulombic efficiency of batteries by enhancing the transformation kinetics of $\mathrm{Na}_{2} \mathrm{~S}$ in the cathode, and also forms a protective In layer on the $\mathrm{Na}$ anode against polysulfide corrosion. Such "cocktail optimized" electrolyte allows stable cycling of room-temperature $\mathrm{Na}-\mathrm{S}$ batteries with high-energy density. These key findings open up a new direction to inspire revolutionary improvements in the performance of room-temperature $\mathrm{Na}-\mathrm{S}$ batteries. This electrolyte design strategy can also be extended to a wide range of Na-based rechargeable battery systems (e.g., $\mathrm{Na}$-oxygen, $\mathrm{Na}$-selenium, and $\mathrm{Na}$-iodine batteries), and boost the development of low-cost and high-performance energy storage devices.

\section{Methods}

Preparation and characterization of electrolytes. Bis(trifluoromethane)sulfonimide sodium salt (NaTFSI, DoDoChem, 99.8\%), lithium bis(trifluoromethanesulfonyl)imide (LiTFSI, DoDoChem, $99.8 \%$ ) and indium triiodide $\left(\mathrm{InI}_{3}\right.$, Sigma Aldrich, $99.998 \%$ ) additives were fully dried at $80^{\circ} \mathrm{C}$ for $24 \mathrm{~h}$ before use. The employed electrolyte solvents contained triethylene glycoldimethyl ether (TEGDME, DoDoChem, 98\%), propylene carbonate (PC, DoDoChem, 99.98\%) and fluoroethylene carbonate (FEC, DoDoChem, 99.95\%). All procedures for electrolyte preparation were carried out in an Ar-filled glove box (MBraun) with the concentrations of moisture and oxygen below $0.5 \mathrm{ppm}$.

The ionic conductivities of the electrolytes were measured by electrochemical impedance spectrum (EIS) from $100 \mathrm{kHz}$ to $1 \mathrm{~Hz}$ with an alternating current amplitude of $5 \mathrm{mV}$ on a VMP3 multichannel electrochemical station (Bio Logic Science Instruments, France). The test cells were assembled by soaking two stainless steel blocking electrodes in electrolyte samples. Prior to the conductivity measurements, the cells were kept at each test temperature (from 0 to $90^{\circ} \mathrm{C}$ ) for 30 $\mathrm{min}$ to reach thermal equilibrium. The electrochemical stability windows of the electrolytes were determined by linear sweep voltammograms performed on $\mathrm{Na}$ / stainless steel cells at $25^{\circ} \mathrm{C}$. The LSVs were measured from open circuit potential to $6 \mathrm{~V}\left(\mathrm{vs} . \mathrm{Na}^{+} / \mathrm{Na}\right)$ at a scan rate of $5 \mathrm{mV} \mathrm{s}^{-1}$ on the VMP3 electrochemical station. To evaluate the compatibility of electrolyte with $\mathrm{Li}$ or $\mathrm{Na}$ metal, galvanostatic cycling measurements consisting of repeated 2-h charge and 2-h discharge cycles were performed on a symmetrical $\mathrm{Li} / \mathrm{Li}$ or $\mathrm{Na} / \mathrm{Na}$ cells at $0.1 \mathrm{~mA} \mathrm{~cm}^{-2}$. The $\mathrm{Na}$ polysulphide dissolution experiments were carried out as follows: $\mathrm{Na}_{2} \mathrm{~S}$ and $\mathrm{S}$ with a mole ratio of $1: 7(1.3$ and $3.7 \mathrm{mg})$ were mixed and added in $10 \mathrm{~mL}$ electrolyte solvents, and kept at $60^{\circ} \mathrm{C}$ to record the color changes along with the aging time. Corresponding UV-Vis spectra were collected with a SEC 2000 UV-Visible spectrophotometer (ALS Co., Ltd.). The viscosity of the electrolytes was performed by the Ubbelohde viscometer (Minbo Co., Ltd.) at $25^{\circ} \mathrm{C}$.

Assembly and characterization of Na-S batteries. The preparation for multiporous carbon fibers (MPCFs) is provided in Supplementary Information. The cathode material, S@MPCF, was prepared following a melt-diffusion strategy. 

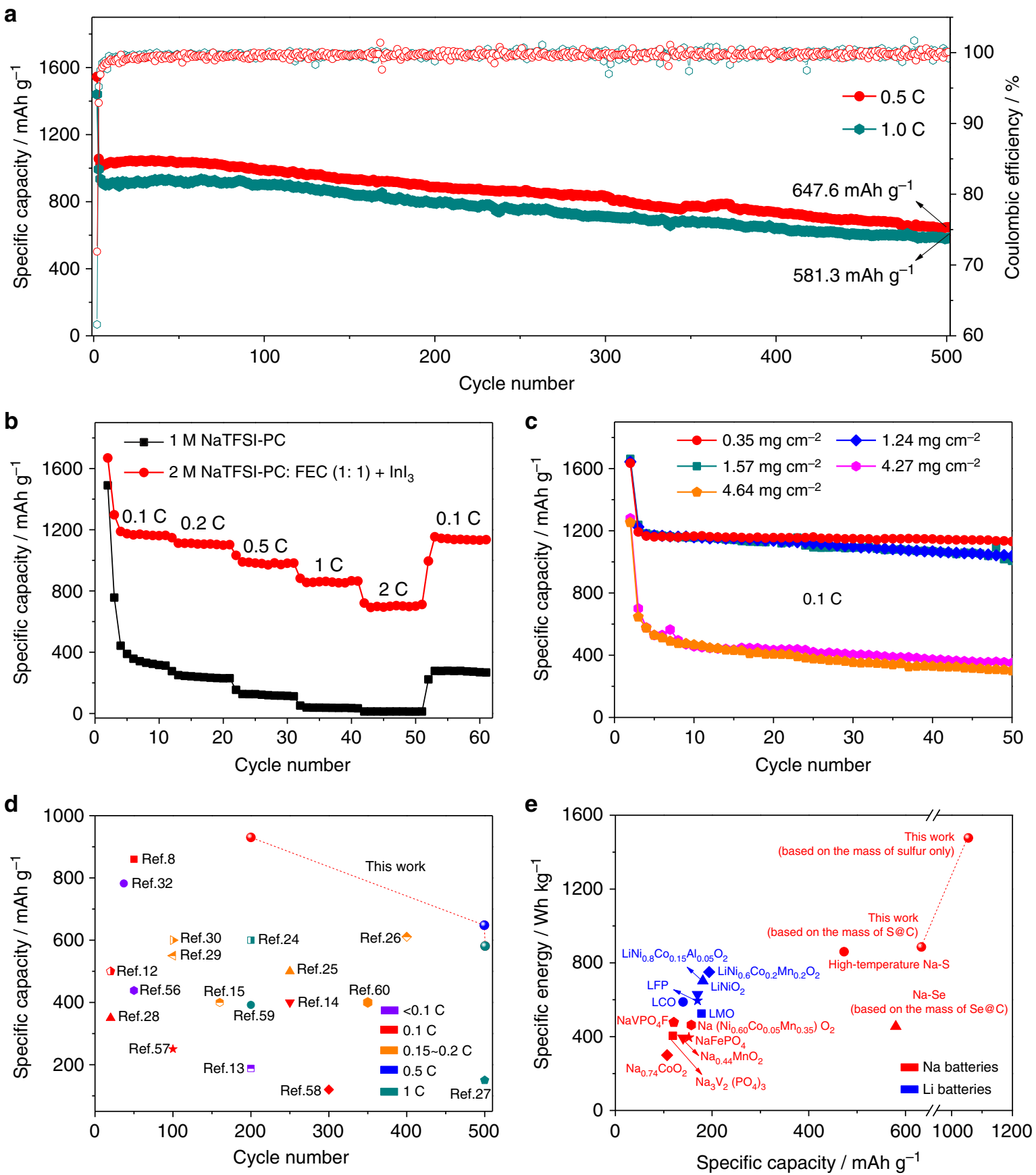

Fig. 6 Electrochemical performances of $\mathrm{Na} / 2 \mathrm{M} \mathrm{NaTFSI}$ in PC: FEC with $10 \mathrm{mM}$ Inl $_{3} / \mathrm{S} @ \mathrm{MPCF}$ cells. a Long-term cycling performances of $\mathrm{Na} / 2 \mathrm{M} \mathrm{NaTFSI}$

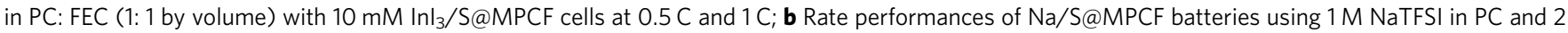
$\mathrm{M} \mathrm{NaTFSI}$ in PC: FEC with $\mathrm{Inl}_{3}$ electrolytes. The sulfur loading in Fig. $6 \mathrm{a}$, b is $\sim 0.36 \mathrm{mg} \mathrm{cm}^{-2}$; c Cycling performances of $\mathrm{Na} / 2 \mathrm{M} \mathrm{NaTFSI}$ in PC: FEC with $\mathrm{Inl}_{3} / \mathrm{S} @ \mathrm{MPCF}$ cells at $0.1 \mathrm{C}$ with different sulfur mass loadings; $\mathbf{d}$ Comparison of practical specific capacities and cycling performances for representative reported room-temperature $\mathrm{Na}-\mathrm{S}$ batteries and this work $8,12-15,24-30,32,37,38,57-61$; e Comparison of practical specific capacities and energy densities of Na batteries and Li batteries with representative reported cathode materials $7,62-64$. The specific capacities and energy densities are evaluated by the mass of cathodic active materials only

MPCFs and nano sulfur powder (Dk Nano technology, Beijing) were ground together at a weight ratio of $4: 6$, and subsequently the S/MPCF mixture in a sealed container were heated at $155^{\circ} \mathrm{C}$ for $10 \mathrm{~h}$ and further heated at $300{ }^{\circ} \mathrm{C}$ for $1 \mathrm{~h}$ in $\mathrm{Ar}$. The S@MPCF electrodes were prepared by a slurry-coating method. The slurry composed of $80 \mathrm{wt} \%$ S@MPCF, $10 \mathrm{wt} \%$ Super-P as conductive agent, and $10 \mathrm{wt} \%$ sodium carboxymethyl cellulose (CMCNa, Macklin, 1500-3100 mpa.s) as binder in deionized water was coated onto a carbon-coated aluminum foil and then dried at $60^{\circ} \mathrm{C}$ under vacuum for $12 \mathrm{~h}$. CR2032 coin cells were assembled in an Ar-filled glove box using glass fiber membranes (Whatman GF/A) for Na-S batteries. The sulfur/electrolyte ratio in each cell was uniformly set at $\sim 50 \mathrm{~g} \mathrm{~L}^{-1}$. The assembled
$\mathrm{Na}-\mathrm{S}$ cells were cycled between 0.8 and $3.0 \mathrm{~V}$ at various charge/discharge rates $1 \mathrm{C}$ $=1675 \mathrm{~mA} \mathrm{~g} \mathrm{~s}^{-1}$ ) on a Land $2001 \mathrm{~A}$ battery testing system at $25^{\circ} \mathrm{C}$. The specific capacity values were calculated based on the mass of sulfur, and the Coulombic efficiency calculated as percentage of the charge capacity in respect to the discharge capacity. Cyclic voltammograms (CVs) of the assembled cells were tested using the VMP3 electrochemical working station at a scanning rate of $0.1 \mathrm{mV} \mathrm{s}^{-1}$. Electrochemical impedance spectra (EIS) of cells was examined using the VMP3 multichannel electrochemical station in the frequency range of $10^{-2}$ to $10^{5} \mathrm{~Hz}$ by applying a disturbance amplitude of $5 \mathrm{mV}$. The cells after designated cycling tests were transferred into a glove box and dissembled for postmortem analysis. The air- 
sensitive electrode samples were rapidly transferred into the vacuum chambers of SEM/XPS/Raman under the protection of vacuum box before the following tests. The ex-situ Raman spectra were obtained with a Lab RAM HR800 (Horiba) using $532 \mathrm{~nm}$ incident radiation.

Theoretical calculations. All structure relaxation and electronic structure calculations were performed with density functional theory with the projector-augmented wave method. The exchange-correlation functional of Perdew, Burke, and Enzerhof (PBE) was employed to analyze the exchange and correlation potentials. The cutoff energy level was set as $500 \mathrm{eV}$, the SCF tolerance level was as $1.0 \times 10^{-5}$ au in geometry optimization, while the SCF tolerance was set as $1.0 \times 10^{-6}$ for energy calculation. The semi-empirical London dispersion corrections of Grimme et al. ${ }^{56}$ were applied to take the dispersion interactions of van der Waals into consideration. For graphite, a $4 \times 4 \times 1$ super cell with a $20 \AA$ vacuum was used.

\section{Data availability}

The data that support the findings of this study are available from the corresponding author upon reasonable request.

Received: 26 March 2018 Accepted: 3 September 2018

Published online: 24 September 2018

\section{References}

1. Dunn, B. et al. Electrical energy storage for the grid: a battery of choices. Science 334, 928-935 (2011).

2. Liang, X. et al. A facile surface chemistry route to a stabilized lithium metal anode. Nat. Energy 2, 17119 (2017).

3. Zhou, T. et al. Twinborn $\mathrm{TiO}_{2}-\mathrm{TiN}$ heterostructures enabling smooth trapping-diffusion-conversion of polysulfides towards ultralong life lithiumsulfur batteries. Energy Environ. Sci. 10, 1694-1703 (2017).

4. Xu, Z. - L. et al. In Situ TEM study of volume expansion in porous carbon nanofiber/Sulfur cathodes with exceptional high-rate performance. Adv. Energ. Mater. 7, 1602078 (2017).

5. Wang, Y.-X. et al. Room-temperature sodium-sulfur batteries: comprehensive review on research progress and cell chemistry. Adv. Energ. Mater. 7, 1602829 (2017).

6. Li, L. et al. SnSb@carbon nanocable anchored on graphene sheets for sodium ion batteries. Nano Res. 7, 1466-1476 (2014).

7. $\mathrm{Lu}, \mathrm{X}$. et al. Advanced intermediate-temperature $\mathrm{Na}-\mathrm{S}$ battery. Energy Environ. Sci. 6, 299-306 (2013).

8. Wei, S. et al. A stable room-temperature sodium-sulfur battery. Nat. Commun 7, 11722 (2016).

9. Hueso, K. B. et al. High temperature sodium batteries: status, challenges and future trends. Energy Environ. Sci. 6, 734-749 (2013).

10. Hueso, K. B. et al. Challenges and perspectives on high and intermediatetemperature sodium batteries. Nano Res. 10, 4082-4114 (2017).

11. Park, C. et al. Room-temperature solid-state sodium/sulfur battery. $J$. Electrochem. Soc. 9, A123-A125 (2006).

12. Seh, Z. W. et al. A highly reversible room-temperature sodium metal anode. ACS Cent. Sci. 1, 449-455 (2015).

13. Ye, H. et al. Amorphous $\mathrm{MoS}_{3}$ as the sulfur-equivalent cathode material for room-temperature Li-S and Na-S batteries. Proc. Natl Acad. Sci. 114, 13091-13096 (2017).

14. Carter, R. et al. A sugar-derived room-temperature sodium sulfur battery with long term cycling stability. Nano Lett. 17, 1863-1869 (2017).

15. Wei, S. et al. Highly stable sodium batteries enabled by functional ionic polymer membranes. Adv. Mater. 29, 1605512 (2017).

16. Zhang, B. W. et al. In situ grown $\mathrm{S}$ nanosheets on $\mathrm{Cu}$ foam: an ultrahigh electroactive cathode for room-temperature Na-S batteries. ACS Appl. Mater. Interf. 9, 24446-24450 (2017).

17. Fan, L. et al. Covalent sulfur for advanced room temperature sodium-sulfur batteries. Nano Energy 28, 304-310 (2016).

18. Yabuuchi, N. et al. Research development on sodium-ion batteries. Chem. Rev. 114, 11636-11682 (2014).

19. Cao, R. et al. Enabling room temperature sodium metal batteries. Nano Energy 30, 825-830 (2016).

20. Cheng, X. B. et al. Toward safe lithium metal anode in rechargeable batteries: a review. Chem. Rev. 117, 10403-10473 (2017).

21. Luo, W. et al. Encapsulation of metallic $\mathrm{Na}$ in an electrically conductive host with porous channels as a highly stable Na metal anode. Nano Lett. 17, 3792-3797 (2017)

22. Zhao, Y. et al. Superior stable and long life sodium metal anodes achieved by atomic layer deposition. Adv. Mater. 29, 1606663 (2017).
23. Wang, A. et al. Processable and moldable sodium-metal anodes. Angew. Chem. Int. Ed. 56, 11921-11926 (2017).

24. Xin, S. et al. A high-energy room-temperature sodium-sulfur battery. $A d v$. Mater. 26, 1261-1265 (2014).

25. Chen, Y.-M. et al. A nitrogen doped carbonized metal-organic framework for high stability room temperature sodium-sulfur batteries. J. Mater. Chem. A 4 , 12471-12478 (2016)

26. Ma, D. et al. New strategy for polysulfide protection based on atomic layer deposition of $\mathrm{TiO}_{2}$ onto ferroelectric-encapsulated cathode: toward ultrastable free-standing room temperature sodium-sulfur batteries. Adv. Func. Mater. 28, 1705537 (2018)

27. Hwang, T. H. et al. One-dimensional carbon-sulfur composite fibers for Na-S rechargeable batteries operating at room temperature. Nano Lett. 13, $4532-4538$ (2013).

28. Bauer, I. et al. Shuttle suppression in room temperature sodium-sulfur batteries using ion selective polymer membranes. Chem. Commun. 50, 3208-3210 (2014)

29. Yu, X. et al. Ambient-temperature sodium-sulfur batteries with a sodiated nafion membrane and a carbon nanofiber-activated carbon composite electrode. Adv. Energ. Mater. 5, 201500350 (2015).

30. Yu, X. et al. A performance enhancement and mechanistic studies of roomtemperature sodium-sulfur batteries with a carbon-coated functional nafion separator and a $\mathrm{Na}_{2} \mathrm{~S} /$ activated carbon nanofiber cathode. Chem. Mater. 28 , 896-905 (2016)

31. Kohl, M. et al. Hard carbon anodes and novel electrolytes for long-cycle-life room temperature sodium-sulfur full cell batteries. Adv. Energ. Mater. 6 1502815 (2016).

32. Kim, I. et al. Sodium polysulfides during charge/discharge of the roomtemperature $\mathrm{Na} / \mathrm{S}$ battery using TEGDME electrolyte. J. Electrochem. Soc. $\mathbf{1 6 3}$, A611-A616 (2016).

33. Ponrouch, A. et al. In search of an optimized electrolyte for Na-ion batteries. Energy Environ. Sci. 5, 8572-8583 (2012).

34. Gao, J. et al. Effects of liquid electrolytes on the charge-discharge performance of rechargeable lithium/sulfur batteries: electrochemical and in-Situ X-ray absorption spectroscopic studies. J. Phys. Chem. C. 115, 25132-25137 (2011)

35. Bhattacharyya, D. N. et al. Reactivities and conductivities of ions and ion pairs in polymerization processes. J. Phys. Chem. 9, 612-623 (1965).

36. Bhattacharyya, D. N. et al. Studies of ions and ion pairs in tetrahydrofuran solution. Alkali metal salts of tetraphenylboride. J. Phys. Chem. 69, 608-611 (1965).

37. Yu, X. et al. Room-temperature sodium-sulfur batteries with liquid-phase sodium polysulfide catholytes and binder-free multiwall carbon nanotube fabric electrodes. J. Phys. Chem. C. 118, 22952-22959 (2014).

38. Wang, Y. X. et al. Achieving high-performance room-temperature sodiumsulfur batteries with S@interconnected mesoporous carbon hollow nanospheres. J. Am. Chem. Soc. 138, 16576-16579 (2016)

39. Gong, D. et al. An iodine quantum dots based rechargeable sodium-iodine battery. Adv. Energ. Mater. 7, 1601885 (2017).

40. Croce, F. et al. A safe, high-rate and high-energy polymer lithium-ion battery based on gelled membranes prepared by electrospinning. Energy Environ. Sci. 4, 921-927 (2011).

41. Suo, L. et al. A new class of solvent-in-salt electrolyte for high-energy rechargeable metallic lithium batteries. Nat. Commun. 4, 1481 (2013)

42. Wang, L. et al. Influence of fluoroethylene carbonate as co-solvent on the high-voltage performance of $\mathrm{LiNi}_{1 / 3} \mathrm{Co}_{1 / 3} \mathrm{Mn}_{1 / 3} \mathrm{O}_{2}$ cathode for lithium-ion batteries. Electrochim. Acta 191, 8-15 (2016).

43. Liumin, S. et al. "Water-in-salt" electrolyte enables high-voltage aqueous lithium-ion chemistries. Science 350, 938-943 (2015).

44. Liang, Z. et al. Polymer nanofiber-guided uniform lithium deposition for battery electrodes. Nano Lett. 15, 2910-2916 (2015).

45. Liu, M. et al. An efficient $\mathrm{Li}_{2} \mathrm{~S}$-based lithium-ion sulfur battery realized by a bifunctional electrolyte additive. Nano Energy 40, 240-247 (2017).

46. Ren, Y. X. et al. A self-cleaning Li-S battery enabled by a bifunctional redox mediator. J. Power Sources 361, 203-210 (2017).

47. Wenzel, S. et al. Thermodynamics and cell chemistry of room temperature sodium/sulfur cells with liquid and liquid/solid electrolyte. J. Power Sources 243, 758-765 (2013).

48. Abraham, K. M. et al. The lithium surface film in the $\mathrm{Li} / \mathrm{SO}_{2}$ cell. $J$. Electrochem. Soc. 133, 1037-1311 (1986).

49. Chen, X. et al. Reduction mechanism of fluoroethylene carbonate for stable solid-electrolyte interphase film on silicon anode. ChemSusChem 7, 549-554 (2014).

50. Park, Y. et al. Investigation of solid electrolyte interface (SEI) film on $\mathrm{LiCoO}_{2}$ cathode in fluoroethylene carbonate (FEC)-containing electrolyte by $2 \mathrm{D}$ correlation X-ray photoelectron spectroscopy (XPS). J. Mol. Struct. 1069, 157-163 (2014).

51. Zheng, J. et al. Electrolyte additive enabled fast charging and stable cycling lithium metal batteries. Nat. Energy 2, 17012 (2017). 
52. Zhou, D. et al. A novel lithiated silicon-sulfur battery exploiting an optimized solid-like electrolyte to enhance safety and cycle life. Small 13, 1602015 (2017).

53. Wu, H. L. et al. In situ Raman spectroscopy of sulfur speciation in lithiumsulfur batteries. ACS Appl. Mater. Interf. 7, 1709-1719 (2015).

54. Kazuyuki, T. et al. Lithium cations tightly bound to polychalcogenides: synthesis and solid-state structures of $\mathrm{Li}_{2} \mathrm{~S}_{6}, \mathrm{Li}_{2} \mathrm{~S}_{4}$ and $\mathrm{Li}_{2} \mathrm{Se}_{5}$. Inorg. Chem. 32 , 4317-4323 (1993).

55. Hagen, M. et al. In-situ Raman investigation of polysulfide formation in Li-S cells. J. Electrochem. Soc. 160, A1205-A1214 (2013).

56. Grimme, S. Semiempirical GGA-type density functional constructed with a long-range dispersion correction. J. Comput. Chem. 27, 1787-1799 (2006).

57. Yue, J. et al. High-performance all-inorganic solid-state sodium-sulfur battery. ACS Nano 11, 4885-4891 (2017).

58. Ceylan Cengiz, E. et al. Investigation of the effect of using $\mathrm{Al}_{2} \mathrm{O}_{3}$-nafion barrier on room-temperature Na-S batteries. J. Phys. Chem. C. 121, 15120-15126 (2017).

59. Lu, Q. et al. Freestanding carbon fiber cloth/sulfur composites for flexible room-temperature sodium-sulfur batteries. Energy Storage Mater. 8, 77-84 (2017).

60. $\mathrm{Hu}, \mathrm{L}$. et al. Ultramicroporous carbon through an activation-free approach for Li-S and Na-S batteries in carbonate-based electrolyte. ACS Appl. Mater. Interf. 9, 13813-13818 (2017).

61. Qiang, Z. et al. Ultra-long cycle life, low-cost room temperature sodium-sulfur batteries enabled by highly doped $(\mathrm{N}, \mathrm{S})$ nanoporous carbons. Nano Energy 32, 59-66 (2017)

62. Xiang, X. et al. Recent advances and prospects of cathode materials for sodium-ion batteries. Adv. Mater. 27, 5343-5364 (2015).

63. Etacheri, V. et al. Challenges in the development of advanced Li-ion batteries: a review. Energy Environ. Sci. 4, 3243-3262 (2011).

64. Zeng, L. et al. A flexible porous carbon nanofibers-selenium cathode with superior electrochemical performance for both Li-Se and Na-Se batteries. Adv . Energ. Mater. 5, 1401377 (2015).

\section{Acknowledgements}

We would like to acknowledge the support by National Key Basic Research Program of China (No. 2014CB932400), National Natural Science Foundation of China (No. U1401243), Shenzhen Technical Plan Project (No. JCYJ20150529164918735 and JCYJ20170412170911187), Guangdong Technical Plan Project (No. 2015TX01N011), the Australian Renewable Energy Agency project (ARENA 2014/RND106), and the ARC Discovery Project (DP170100436). We thank Dr. Peng Li from Nanjing University of
Aeronautics and Astronautics for conducting the first-principle calculations and Dr. Ming Liu from Delft University of Technology for giving valuable advice on the characterization of polysulfide shuttle phenomenon. D. Shanmukaraj would like to thank IKERMUGIKORTASUNA, Basque mobility grant for a short stay at University of Technology Sydney (UTS), Sydney, Australia.

\section{Author contributions}

B.L., M.A., and G.W. conceived and designed this work; X.X. and D.Z. performed the experiments and wrote the manuscript. X.Q. designed the synthesis of multiporous carbon fibers materials. K.L. contributed to the analysis of Raman spectrum. F.K., D.S., and T.R. discussed the results and participated in the preparation of the paper.

\section{Additional information}

Supplementary Information accompanies this paper at https://doi.org/10.1038/s41467018-06443-3.

Competing interests: The authors declare no competing interests.

Reprints and permission information is available online at http://npg.nature.com/ reprintsandpermissions/

Publisher's note: Springer Nature remains neutral with regard to jurisdictional claims in published maps and institutional affiliations.

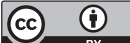

Open Access This article is licensed under a Creative Commons Attribution 4.0 International License, which permits use, sharing, adaptation, distribution and reproduction in any medium or format, as long as you give appropriate credit to the original author(s) and the source, provide a link to the Creative Commons license, and indicate if changes were made. The images or other third party material in this article are included in the article's Creative Commons license, unless indicated otherwise in a credit line to the material. If material is not included in the article's Creative Commons license and your intended use is not permitted by statutory regulation or exceeds the permitted use, you will need to obtain permission directly from the copyright holder. To view a copy of this license, visit http://creativecommons.org/ licenses/by/4.0/

(C) The Author(s) 2018 